\title{
Mechanical response of a lined pipe under dynamic impact
}

\author{
Obeid Obeid", a , Giulio Alfano ${ }^{1, b}$, Hamid Bahai $^{1, c}$, Hussam Jouhara ${ }^{1, \mathrm{~d}}$ \\ ${ }^{1}$ College of Engineering, Design and Physical Sciences, Brunel University, UB8 3PH \\ Uxbridge, UK \\ a obeid.obeid@brunel.ac.uk, biulio.alfano@brunel.ac.uk, ${ }^{\mathrm{c}}$ hamid.bahai@brunel.ac.uk, \\ dhussam.jouhara@brunel.ac.uk
}

\begin{abstract}
An experimental and numerical investigation on the mechanical response of a lined pipe (compound pipe) under a dynamic impact is presented. The influence of the impact energy has been studied in terms of the depth of the dent formed, and of the strains and residual stresses. To this end, a three-dimensional explicit dynamic non-linear finite element model has been developed and successfully validated against the results of impact-test experiments conducted on pipes made of AISI 10305 steel, with and without the AISI304 stainless steel liner. The validation was made by comparing numerically computed strains with those measured by strain gauges, as well as in terms of permanent deformation. The model is then utilized to evaluate the residual stresses, the amount of energy dissipation and the velocity of impact process as a function of different pipes (i.e. with or without liner) and of the free drop heights.
\end{abstract}

Keywords: Lined pipes; Dynamic impact; Residual stresses; Energy; Velocity

\begin{tabular}{|ll|}
\hline \multicolumn{2}{|l|}{ Nomenclature } \\
$d$ & Dent depth (mm) \\
$D$ & Pipe outer diameter (mm) \\
$\mathrm{D}_{\text {carbon }}$ & Outer diameter of undeformed C-Mn pipe $(\mathrm{mm})$ \\
$\mathrm{D}_{\text {stainless }}$ & Outer diameter of undeformed AISI304 pipe (mm) \\
$E_{T O T}$ & Total energy (W) \\
$E_{I}$ & Internal energy (W) \\
$E_{V D}$ & Viscous dissipation energy (W) \\
$E_{K E}$ & Kinetic energy (W) \\
$E_{F D}$ & Frictional dissipation energy (W) \\
$E_{W}$ & Work energy (W) \\
$E_{S E}$ & Recoverable (elastic) strain energy (W) \\
$E_{P D}$ & Plastic dissipation energy (W) \\
$E_{I W}$ & Internal work energy (W) \\
$E_{E W}$ & External work energy (W) \\
\hline
\end{tabular}




\begin{tabular}{|ll|}
\hline$g$ & Acceleration of gravity $\left(\mathrm{m} / \mathrm{s}^{2}\right)$ \\
$\mathrm{H}_{\text {carbon }}$ & Dent depth of C-Mn pipe $(\mathrm{mm})$ \\
$\mathrm{H}_{\text {stainless }}$ & Dent depth of AISI304 pipe $(\mathrm{mm})$ \\
$\mathrm{I}$ & Height of punched pipe $(\mathrm{mm})$ \\
$\mathrm{S}$, Mises & Von Mises Stress $(\mathrm{N})$ \\
$v$ & Velocity of free drop $(\mathrm{m} / \mathrm{s})$ \\
$\mathrm{W}$ & Width of punched pipe $(\mathrm{mm})$ \\
$Y$ & strength coefficient \\
BCAST & Brunel Centre for Advanced Solidification Technology \\
EPRG & European Pipeline Research Group \\
PDMA & Pipeline Defect Assessment Manual \\
PHMSA & Pipeline and Hazard Materials Safety Administration \\
TFP & Tight Fit Pipe \\
$\bar{\varepsilon}^{p}$ & equivalent plastic strain (m/m) \\
$\dot{\bar{\varepsilon}}^{p}$ & equivalent plastic strain rate $(1 / \mathrm{s})$ \\
\hline
\end{tabular}

\section{Introduction}

Oil \& Gas pipelines face cyclic loading generated by fluid pressure changes, especially in the case of offshore pipelines which have high internal pressure, or as a result of waves and currents, the latter possibly leading to vortex-induced vibrations [1].

On the other hand, corrosive production fluids make the use of C-Mn steel pipe for flow line impossible, so that the need for corrosion mitigation is required [2]. One alternative is the use of a lined pipe, consisting of a thinner inner layer (the liner) and outer layer (backing steel) [3]. The liner is made of corrosion resistant alloy (CRA) such as Alloy625, 304 and 316L stainless steel (SS) whilst the backing steel is made of low-cost carbon steel in which Magnesium Mn percentage is over 1\% [4]. A lined pipe is sufficiently a good option for reasonable cost and high corrosion resistance for pipeline design life. However, due to the use of corrosion resistant liner, the thickness of C-Mn pipe can be significantly reduced. In this case, the lined pipe can be damaged either during construction process, or by third party interference such as dropped object or trawl gear impact of fishing boats. If the pipeline with liner is dented due to an impact, it could cause loss of pressure containment, hydrocarbon leak, and catastrophic consequences. Therefore, if the dent size exceeds the allowable size, it must be repaired.

Pipeline and Hazard Materials Safety Administration PHMSA [5] reported that the external interference was responsible for $27 \%$ of failures in liquid transmission pipelines and for $31 \%$ of failures on natural gas pipelines in the USA. Furthermore, the failure resulted from third party damage could be either immediate or not immediate. In the latter case, generated cracks could grow and cause pipe fatigue failure in service after short time of the first impact 
because of the aforementioned cyclic nature of loading. Thus, dented pipes require more monitoring and the high localized stresses in the dented zone need to be evaluated.

In the last century, great effort has been devoted to the analytically determination of stresses in dented pipes. Durkin [6] proposed an analytical model to determine the remaining strength of dented pipe subjected to axial loads and moments. The predicted results of ultimate strength were within 5\% compared with FE results carried out by Shell Research. The stress concentration, based on an analytical approach in the elastic domain, has been investigated for a dent on a pressurised cylinder by Seng et al. [7]. The maximum concentration stress occurred in the long dent compared with local and short dents. The effects of gouges, dents and weld seams on the fatigue life of pipelines subjected to internal pressure has been addressed in the analytical method developed by Fowler et al. [8]. The dented pipes joined by girth welds had a greater impact on the fatigue life than those joined by longitudinal welds. Furthermore, increasing the gouge depth led to reduce the fatigue life. The maximum stress concentration occurred with the largest dents.

In recent years, the nonlinear finite element code ABAQUS has been often used to numerically simulate the indentation in pipelines. Netto et al. [9] studied the effect on the burst pressure capacity of corroded pipes with different materials and different geometry of corroded zone. The results pointed out that increasing the dent length led to decrease the burst capacity. A new methodology to evaluate the fatigue life behaviour of dented pipes subjected to internal pressure has been examined by Pinheiro and Pasqualino [10]. It was found that strains tangent to the dent periphery were compressive whereas their perpendicular counterparts were tensile. A series of dent and burst tests have been conducted in the work of Allouti et al. [11] to study the effect of dent depth on the internal pressure of the pipelines. The Vickers microhardeness values taken from the dent centre were higher by $30 \%$ than those taken from the pipe end. However, one of the most critical problems in lined pipes is the stress/strain behaviour under dynamic impact and it is observed that, to the best of the authors' knowledge, no articles in the literature have addressed the effect of dynamic impact on the lined pipes (compound pipes) using a non-liner numerical explicit approach to account for material (plasticity) and geometric nonlinearities for a dynamic high-speed drop test.

Therefore, the main objective of this work is to numerically and experimentally study the stress and strain behaviour of small-scale lined pipe specimens, with and without liner, subjected to a direct impact with different impact energies. To achieve this objective, a 
weight of $200 \mathrm{~kg}$ equipped with a semi-spherical indenter with diameter of $51.75 \mathrm{~mm}$ is dropped freely from $1,1.5$ and $2 \mathrm{~m}$ on specimens of carbon-manganese steel (C-Mn) pipe without liner (case A) and with liner (case B). Strain results are obtained by mounting strain gauges to record the strain history during the whole impact process.

\section{Experimental specimens and materials}

Experiments were conducted for two groups of pipes. The first one, case A, consists of C-Mn pipes without liner. The second group, case B, consists of lined pipes composed of C-Mn outer pipes cladded with AISI304 stainless-steel pipes internally. Each specimen in both cases has a total length of $200 \mathrm{~mm}$.

\subsection{Tight fit pipe process and specimens}

Specimens of lined pipes used for impact tests were manufactured at Brunel University (BCAST lab). To manufacture the lined pipe, a pre-heat treatment, which is in general known as tight fit pipe (TFP), was used. It consisted of heating up the outer pipe inside a furnace to $500{ }^{\circ} \mathrm{C}$ and cooling down the inner pipe in Liquid Nitrogen to $-200{ }^{\circ} \mathrm{C}$ [4]. After that, the shrunk AISI304 pipe is inserted inside the heated C-Mn specimen as shown in Fig. 1. The chemical compositions of AISI 10305 and AISI304 are given in Table 1.

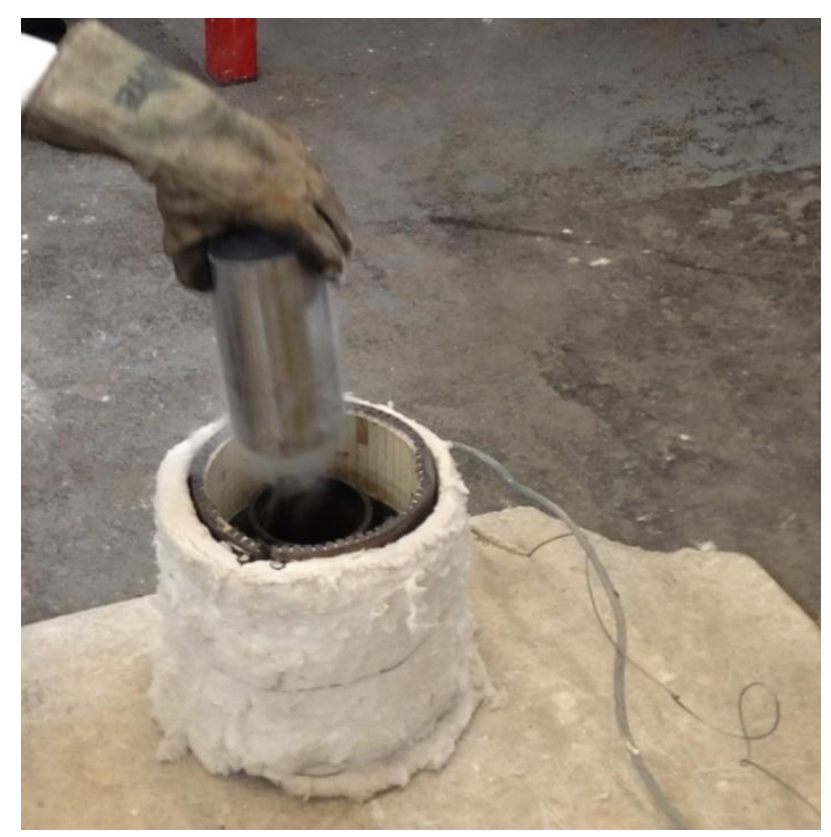

Fig. 1 Inserting the liner (AISI304) inside the heated C-Mn pipe 
Table 1 Chemical composition of AISI 10305 (C-Mn) and AISI304

\begin{tabular}{l|l|l|l|l|l|l|l|l}
\hline Steel grade & C \% & Si \% & Mn \% & P \% & S \% & Al \% & Cr \% & Ni \% \\
\hline AISI 10305 & $\leq 0.17$ & $\leq 0.35$ & $\leq 1.2$ & $\leq 0.045$ & $\leq 0.045$ & $\geq 0.02$ & - & - \\
\hline AISI304 & $\leq 0.08$ & $\leq 1$ & $\leq 2$ & $\leq 0.045$ & $\leq 0.03$ & - & $18-20$ & $8-10.5$ \\
\hline
\end{tabular}

The outer pipe was cut from a AISI $10305 \mathrm{C}-\mathrm{Mn}$ steel cold-drawn pipe with length $\left(\mathrm{L}_{\text {carbon }}\right)$ of $5.8 \mathrm{~m}$. The inner pipe was cut from a AISI304 seamed austenitic stainless steel pipe with length ( $\mathrm{L}_{\text {stainless }}$ ) of $6.0 \mathrm{~m}$. The total length of each test specimen was $200 \mathrm{~mm}$. The outer pipe, C-Mn, has an outer diameter $\left(\mathrm{D}_{\text {carbon }}\right)$ of $114.3 \mathrm{~mm}$ with a variance of $\pm 1.45 \mathrm{~mm}$ whereas its wall thickness $\left(\mathrm{t}_{\text {carbon }}\right)$ is $6.35 \mathrm{~mm}$ with a variance of $\pm 0.35 \mathrm{~mm}$. The AISI304 pipe, the liner, has an external diameter $\left(\mathrm{D}_{\text {stainless }}\right)$ and thickness $\left(\mathrm{t}_{\text {stainless }}\right)$ of $101.6 \mathrm{~mm}$ and $1.5 \mathrm{~mm}$ with variance of \pm 1.1 and $\pm 0.15 \mathrm{~mm}$, respectively.

In addition, the mechanical properties of both materials including the density ( $\rho$ ), Young's modulus $(E)$, yield stress $\left(\sigma_{Y}\right)$, ultimate strength $\left(\sigma_{U T S}\right)$ and Poisson's ratio $(v)$ are given for two pipes in Table 2 .

Table 2 Mechanical properties of materials used in collision experiments

\begin{tabular}{c|c|c|c|c|c}
\hline Steel grade & $\boldsymbol{\rho}\left(\mathrm{kgm}^{-3}\right)$ & $\mathbf{E}(\mathbf{G P a})$ & $\boldsymbol{\sigma}_{\mathbf{Y}}(\mathbf{M P a})$ & $\boldsymbol{\sigma}_{\text {UTS }}(\mathbf{M P a})$ & $\boldsymbol{v}$ \\
\hline AISI 10305 & 7860 & 210 & 349 & 390 & 0.26 \\
\hline AISI304 & 7900 & 198.5 & 265 & 505 & 0.294 \\
\hline
\end{tabular}

\subsection{Experimental apparatus}

The apparatus to conduct the free drop test is depicted in Fig. 2. It is composed of a steel square block with total net weight of $200 \mathrm{~kg}$, equipped with a semi-spherical indenter (denting tool) with diameter of $51.75 \mathrm{~mm}$ at the bottom surface. At the top surface of the block, a metal chain connects the block with a mechanism of pulley to draw the blocks up and down. The block slides up and down freely inside a greasy square chamber. The external wall of the chamber is scaled along the height of chamber which is $3 \mathrm{~m}$. Furthermore, a laser distance measuring tool is used to specify the particular height of free drop precisely from the tip of indenter to the outside surface of pipe (dent centre). After reaching a prescribed height, the chain is released from block. Therefore, the block freely slides down through the chamber 
because of gravity to hit the pipe in the centre of the expected dent region located at the middle section of the pipe.

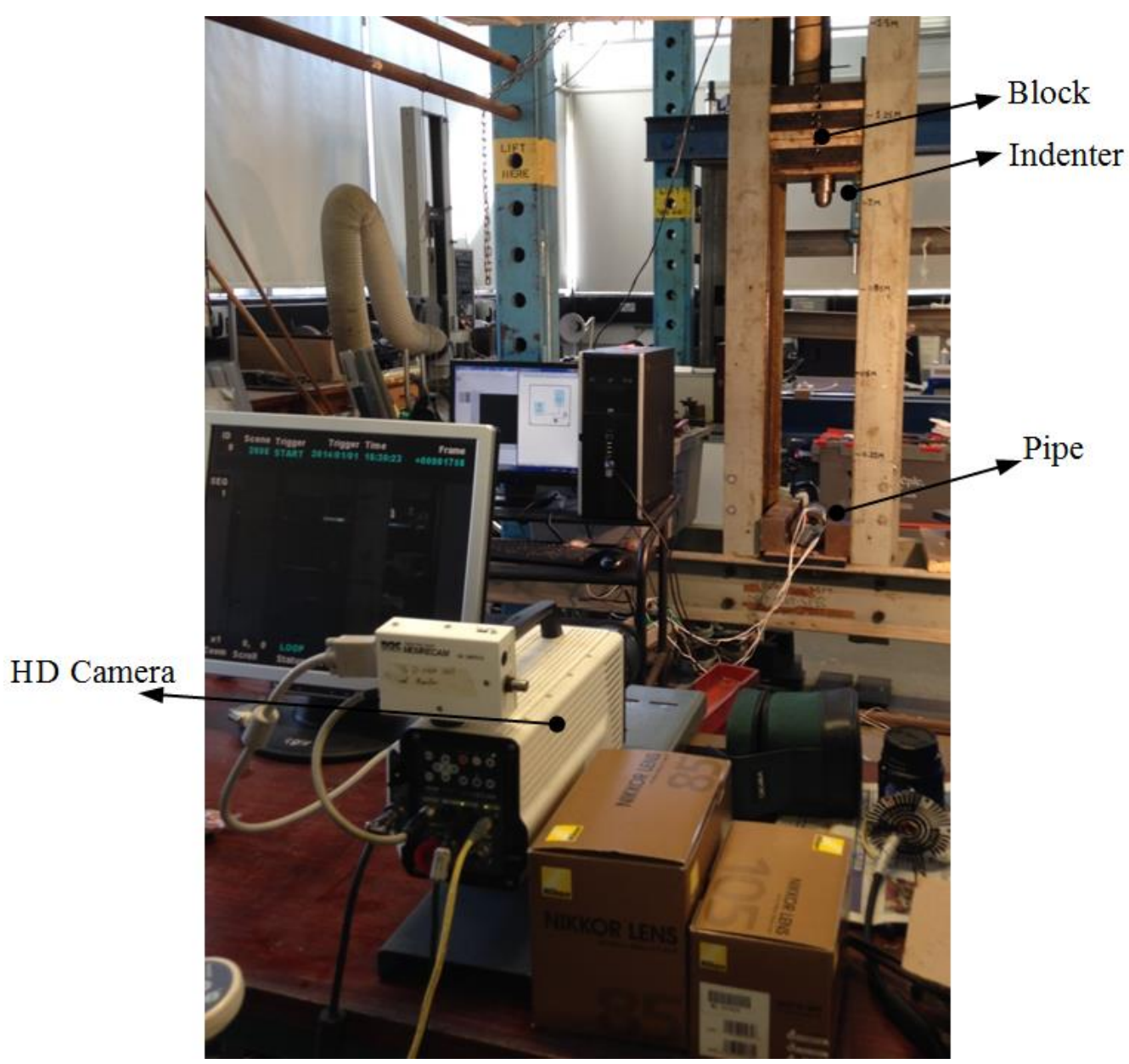

Fig. 2 Impact test apparatus.

Also, Fig. 2 clarifies that the specimen is laid down horizontally on a rigid bottom plate and also placed between two thick rigid plates on its sides with $3 \mathrm{~mm}$ clearance on each side. The mechanical influence of boundary conditions on the results at the dented region is neglected because both pipe ends are free. The displacements on the free ends of the pipe are also much smaller than those at the point where the pipe is dented as discussed later in Section 4.2. Therefore, the influence of the length is very small and can be neglected. The main goal of our experiments is to examine the high levels of strain in the dented region. With this aim, different types of strain gauges were used to record the strain history during the impact process, including strain gauges FRA-5-11 and YEFCA-5-11 for small and large strain, respectively. Furthermore, bi-axial and tri-axial strain gauges were used but only the direct strains in the axial and hoop directions are considered in this study because of the small value of strains in the direction at $45^{\circ}$ (diagonal strain). The procedure applied to install the strain 
gauges on the pipe is corresponding to Standard ASTM E1237. The strain gauges are connected to a data acquisition system (LabVIEW) to record the strain history during the impact process. Afterwards, the stresses are computed from the strain according to Standard ASTM E1561.

The positions of the four strain gauges around the dent were determined first using the FE model to specify locations precisely without damaging the gauges and to acquire high levels of strain closer to dent centre. Strain gauges were firmly fixed on the outside surface using special adhesive glue, polyurethane coating (lacquer), to avoid their debonding during the first and successive collisions. Fig. 3 shows the locations of four strain rosettes (GR1, GR2, GR3 and GR4) symmetrically surrounding the dent centre located at the pipe middle section.

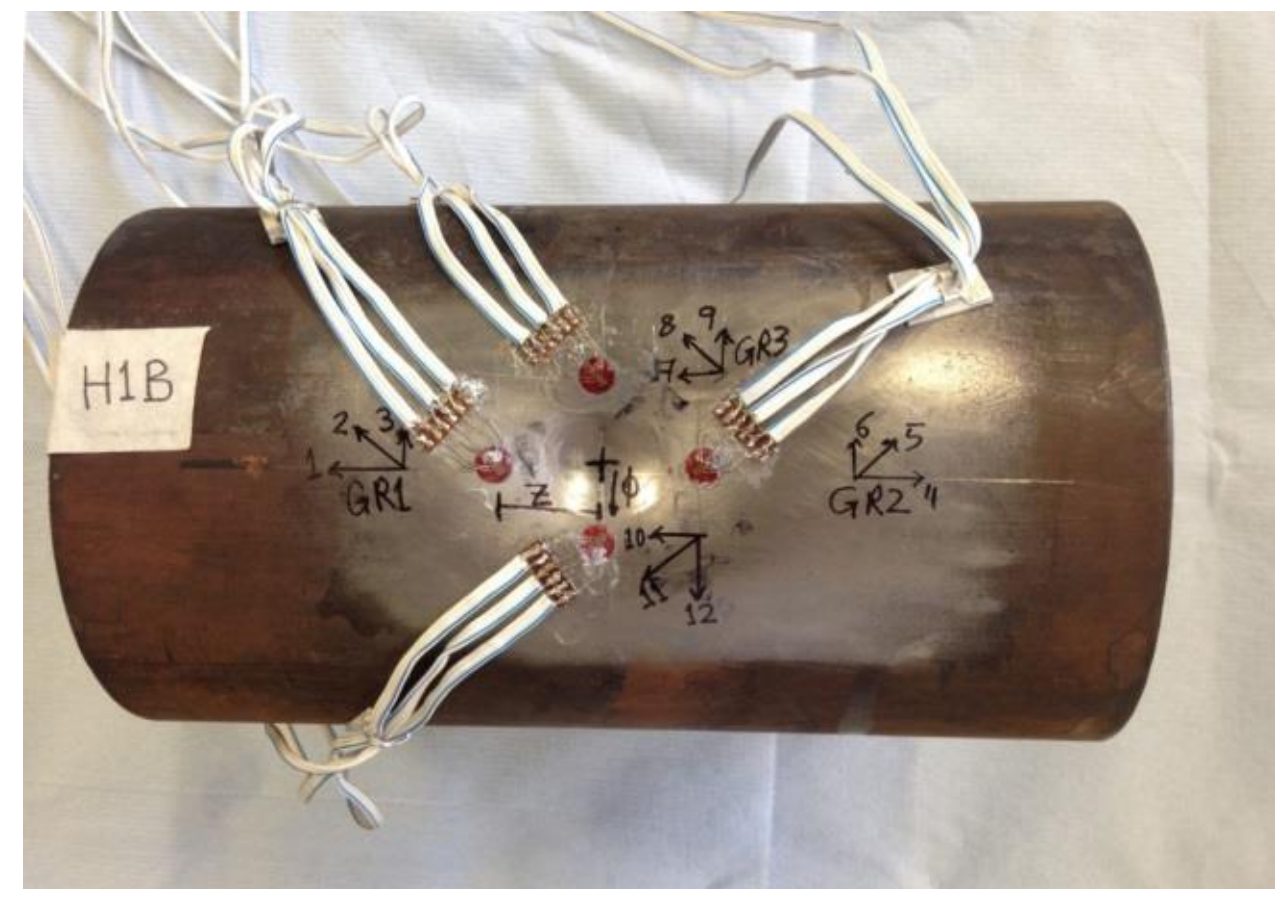

Fig. 3 positions of the strain gauges

\section{Numerical modelling}

3D FE models have been developed to simulate the vertical free drop of a weight from different altitudes resulting in damage of the pipe. Models were executed using a threedimensional dynamic explicit non-linear finite element code, ABAQUS/EXPLICIT 6.13 [12]. In order to precisely simulate the response of the collided pipe to subsequent impacts and spring back, an elastic-plastic constitutive behaviour is adopted using the isotropic Hooke's law whereas the plastic behaviour is accounted for by means of the Von Mises yield criterion, $\sigma_{v}$, with respect to the three principal stresses, $\sigma_{1}, \sigma_{2}$ and $\sigma_{3}$, given as below: 


$$
\sigma_{v}=\sqrt{\frac{1}{2}\left[\left(\sigma_{1}-\sigma_{2}\right)^{2}+\left(\sigma_{2}-\sigma_{3}\right)^{2}+\left(\sigma_{3}-\sigma_{1}\right)^{2}\right]}
$$

The work hardening is based on isotropic hardening rule associated with the equivalent plastic strain rate. With further development of plastic deformation, the equivalent stress criterion, $\sigma_{v}$, accounting for the hardening will be defined as:

$$
\sigma_{v}=Y\left(\bar{\varepsilon}^{p}\right)
$$

where $Y$ is the strength coefficient, $\bar{\varepsilon}^{p}$ is the equivalent plastic strain which is defined through time integration, $t$, of the equivalent plastic strain rate, $\dot{\bar{\varepsilon}}^{p}$, as shown below:

$$
\bar{\varepsilon}^{p}=\int_{t=0}^{t} \dot{\bar{\varepsilon}}^{p} d t
$$

In this problem the equivalent plastic strain rate plays a key role in determining the mechanical properties of punched material $[13,14]$. Typically, the maximum velocity during impact occurs with the initial contact between the indenter and external surface of the pipe, and is reduced rapidly during dent formation. As a result, the pipe material undergoes different strain rates during indentation. Increasing strain rates result in higher stress/strain curves. Furthermore, increasing strain rates lead to higher ultimate strength and lower ductility. Fig. 4 shows the strain rate dependent true stress-true strain curves for C-Mn and AISI304 steels $[15,16]$. 


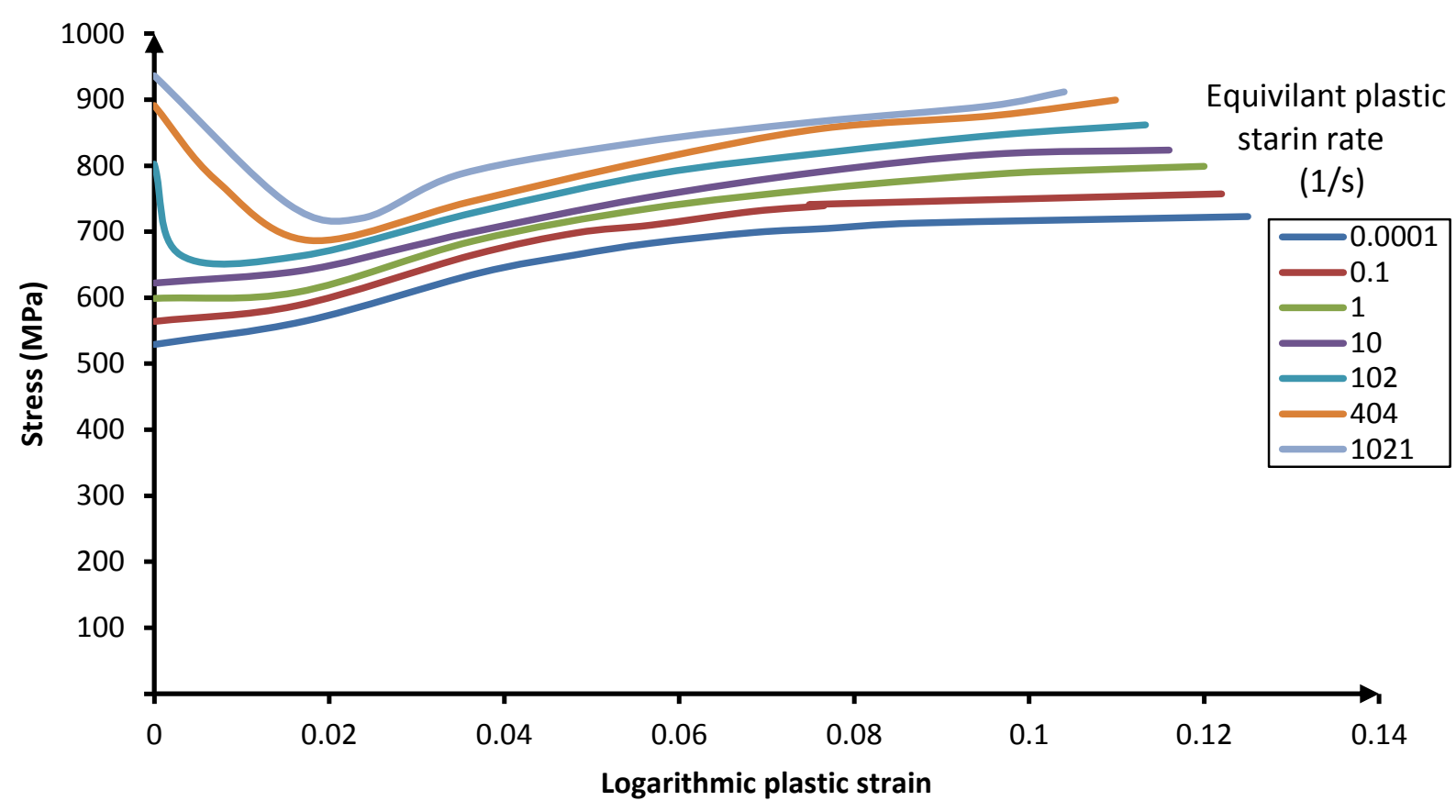

(a)

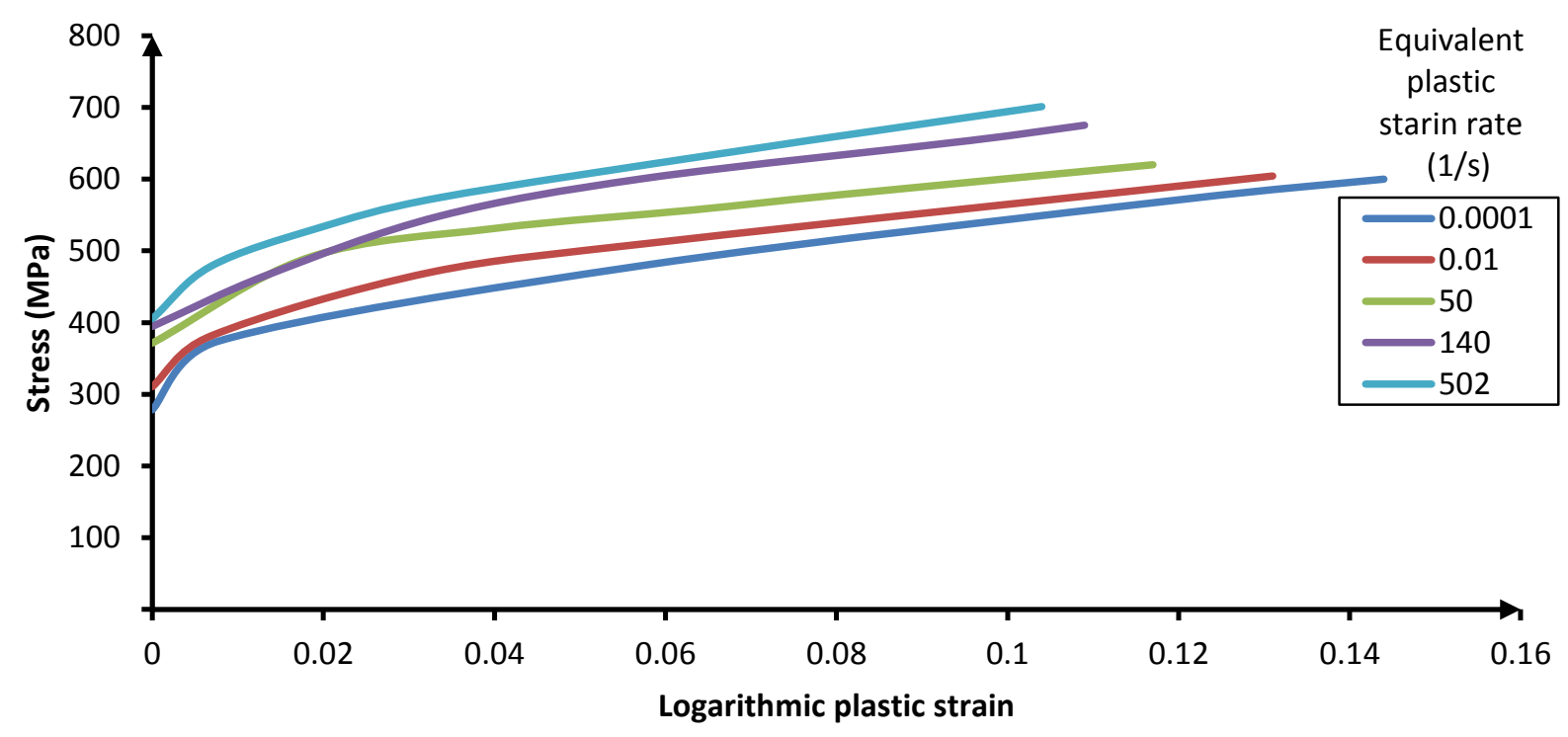

(b)

Fig. 4 Stress vs logarithmic plastic strain corresponding to strain rate for (a) C-Mn pipe [15] and (b)

AISI304 pipe [16].

\subsection{FE mesh of impact components}

The FE model is composed of the outer pipe (C-Mn pipe), the inner pipe (AISI304 pipe), indenter (denting tool), rigid bottom plate and rigid side plate. A lined pipe with $200 \mathrm{~mm}$ length lies down on a bottom plate and trapped between two plates on sides with $3 \mathrm{~mm}$ gap on each side. At the start of the analysis, the tip of indenter is in direct contact with the centre 
of dent located at the pipe middle section, with the initial velocity and the mass equal to those of the dropping weight.

The pipes in both cases A and B, as well as the bottom and two side plates, are discretised with solid 8-node continuum brick elements, with full integration (C3D8) and three translation degrees of freedom at each node. The indenter is modelled using 4-node linear tetrahedron elements (C3D4). All components have a density of $7860 \mathrm{~kg} / \mathrm{m}^{3}$.

To reduce the computational cost, an appropriate mesh refinement is implemented in the numerical analysis, where the size of elements increases outwards the dented region. Furthermore, a quarter model is simulated, because of symmetry with respect to the axial and transverse planes, planes $\mathrm{X}-\mathrm{Y}$ and $\mathrm{Y}-\mathrm{Z}$, respectively. Fig. 5 shows the FE mesh for the main parts of lined pipe impact process, for case B.

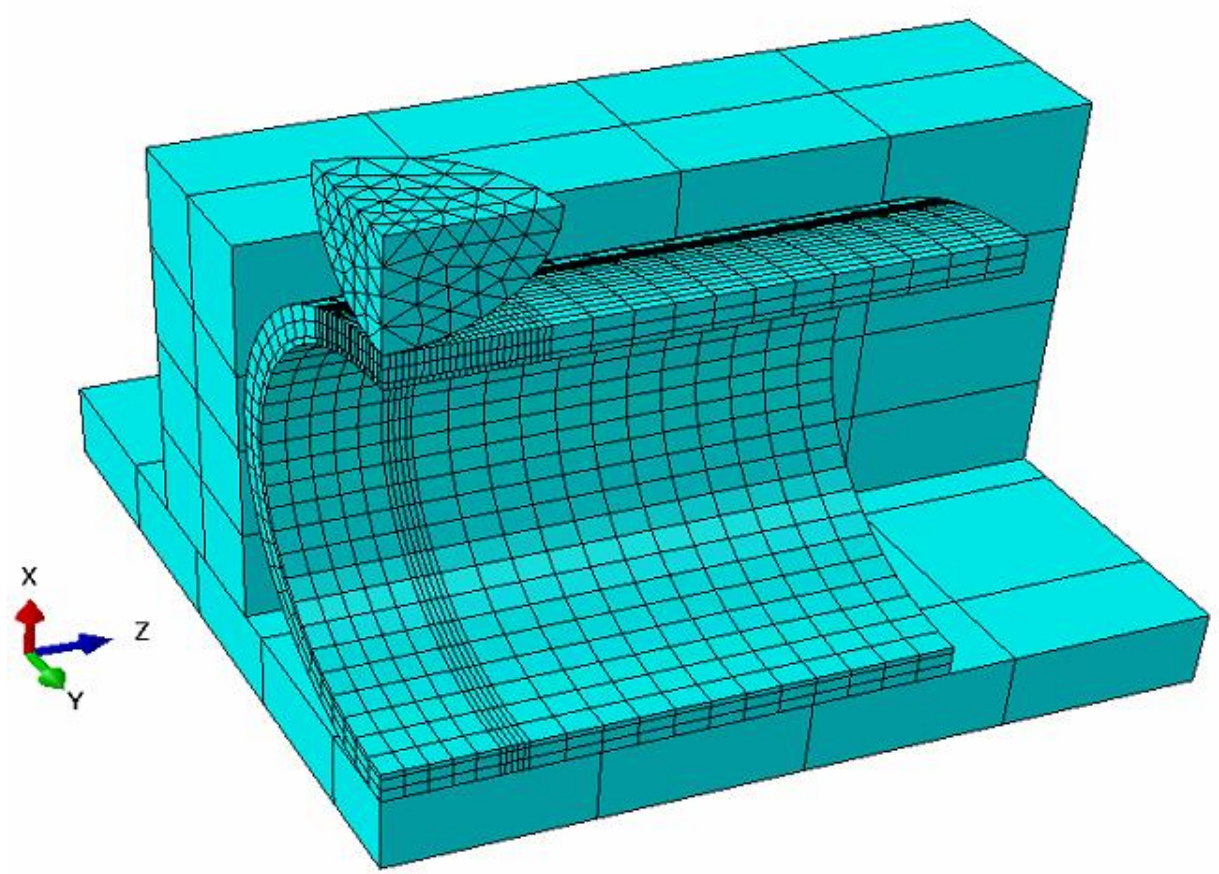

Fig. 5 FE mesh of the quarter lined pipe model, case B.

\subsection{Contact regions, velocity and loads}

Four contact regions are defined in the model. A first one is introduced between the surface of the semi-sphere (denting tool) and the whole surfaces of the C-Mn pipe located in the expected dented region. A second region of contact is located between the inner surface of the C-Mn pipe and the outer surface of AISI304. A third contact region is specified between the external surface of C-Mn pipe and the side plates because of the increasing width of pipe cross section during impact. The last contact occurs between the external surface of the C-Mn 
pipe and the bottom plate. In case A, the second contact area does not exist because AISI304 pipe is not considered. Hard kinematic contact is applied to all contact regions to minimize the penetration of surfaces. Furthermore, the friction coefficient of the tangential behaviour is given a value of 1 to make surface sliding harder.

In the experiment, the weight drops down freely vertically on the pipe from different heights of $1,1.5$ and $2 \mathrm{~m}$. Consequently, neglecting friction and air resistance, the velocity of free drop increases linearly with time to reach its ultimate value as the tip of indenter touches the external surface of the C-Mn pipe, equal to $v=\sqrt{2 g h}$, where $g$ and $h$ are the acceleration of gravity and height, respectively. However, the resistance of air and friction between the square block (weight) and the internal walls of impact apparatus chamber need to be taken into account. The loss in speed value was calculated using video frames recorded for the whole impact operation by a digital high speed camera, MEMRECAM HX-7. It was found out that, in all cases, the actual speed is $9.7 \%$ less than its theoretical value as the tip of indenter touches the pipe. The corrected values of maximum drop speed are 4.0, 4.9 and 5.7 $\mathrm{m} / \mathrm{s}$ when the weight drops vertically from height of $1,1.5$ and $2 \mathrm{~m}$, respectively.

\section{Parametric study}

\subsection{Finite element analysis}

The steps of the FE analysis reflect the procedure employed in the experimental tests. Initially, the indenter freely drops down from a specific height to punch the external surface of C-Mn pipe with a specified velocity. The kinematic energy has been consumed completely to produce an indentation in the mechanically bonded lined pipe before the indenter and pipe retreat vertically as a reaction of collision. The hitting tool and the pipe fall down afterward because of their self-weight. The weights include those of block, spherical indenter, liner and $\mathrm{C}-\mathrm{Mn}$ pipe. The indenter hits the lined pipe frequently, reducing the maximum distance of collision every time because of the kinetic energy being consumed. Consequently, the collision leaves permanent deformation in the lined pipe, which in turn produces residual stresses in the base materials, AISI304 and C-Mn. Fig. 6 shows the position of the indenter with respect to the lined pipe, for case $B$, at different stages of the analysis. When the indenter (with the mass and weight of the block added to it) is pushed up, elastic stresses in the pipe wall are released, which in turn results in rebound the dent depth slightly. 
Nevertheless, the residual stresses remain in the base materials with different levels of plasticity, where the highest level is located in the dented region. Detailed of dynamic simulation procedure is algorithmically sketched in Fig. 6.

\section{DYNAMIC ANALYSIS}

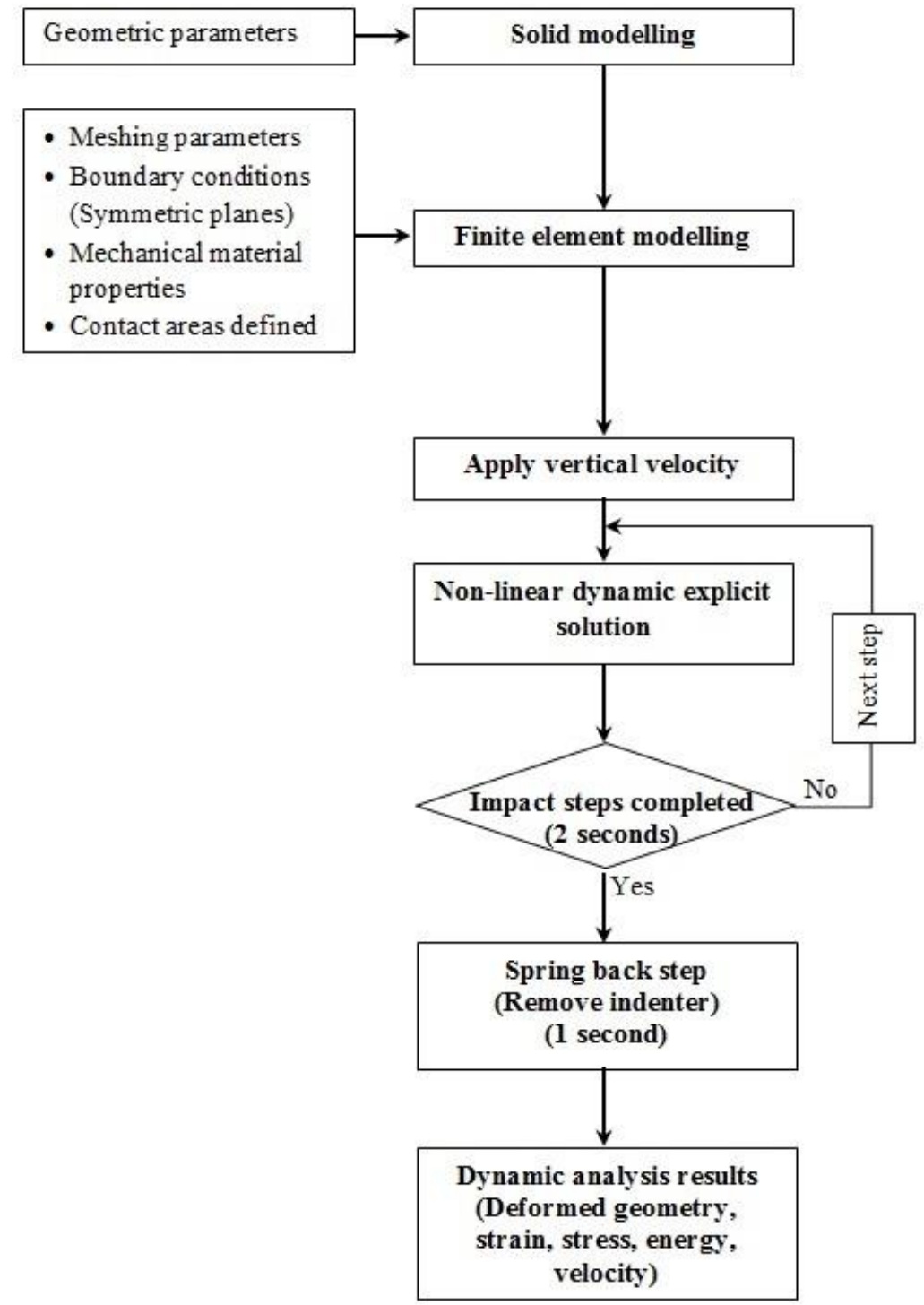

Fig. 6. Algorithmic sketch of the explicit-dynamic numerical analysis

Figure 7 shows the FE deformed configurations at four different times of the process, namely at times $0,7.5,75$ and $250 \mathrm{~ms}$, respectively, compared with the pictures taken by the digital camera, MEMRECAM HX-7. The latter offers full HD resolution up to 2000 frames per second (fps), which is practically a good choice to capture the sequential strikes after the first collision between the indenter and pipe. 


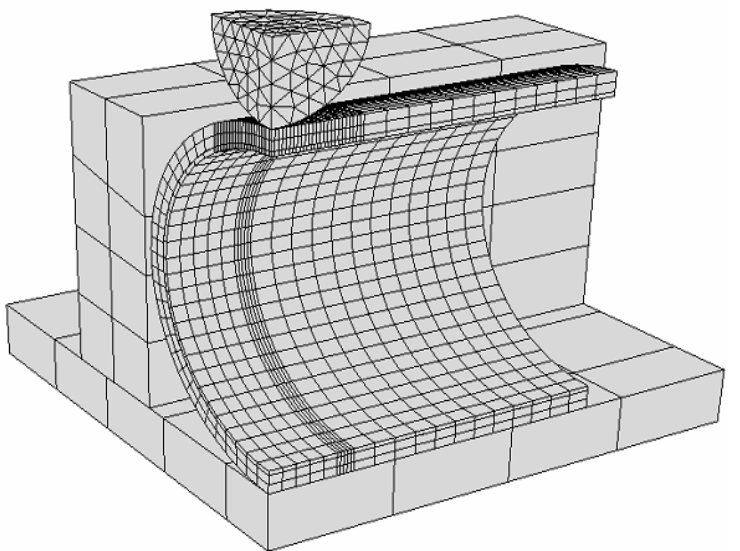

(a)

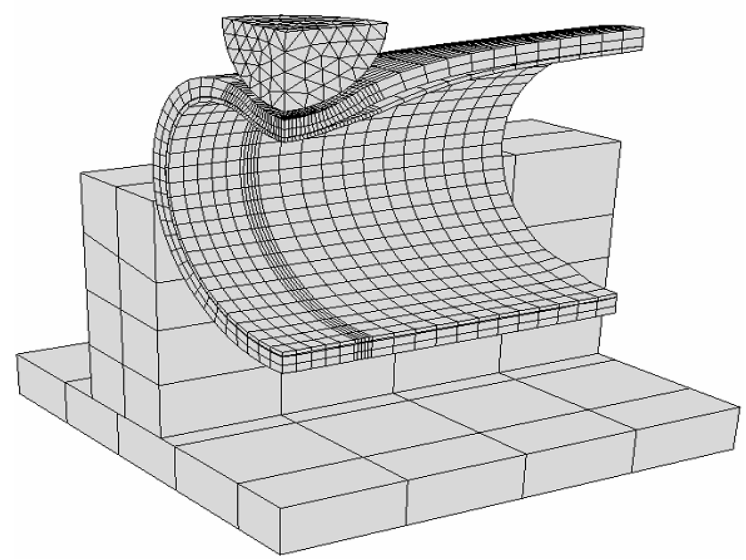

(c)

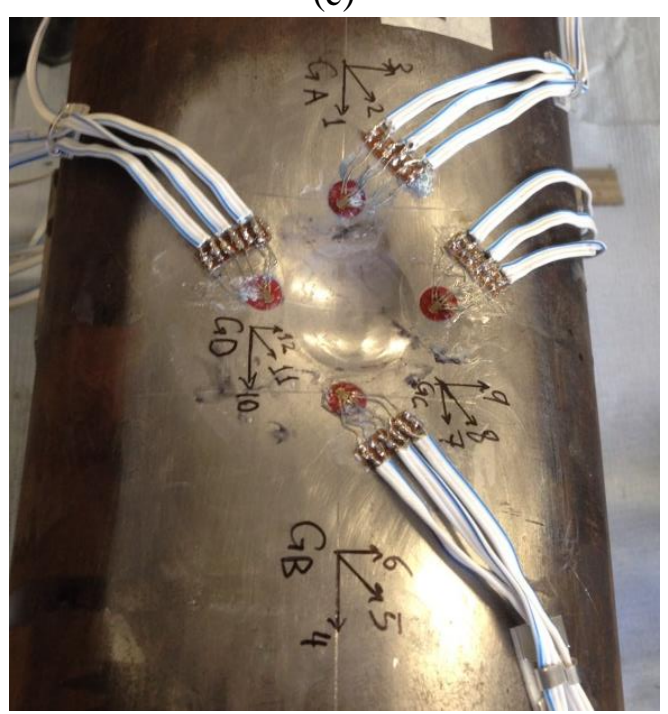

(e)

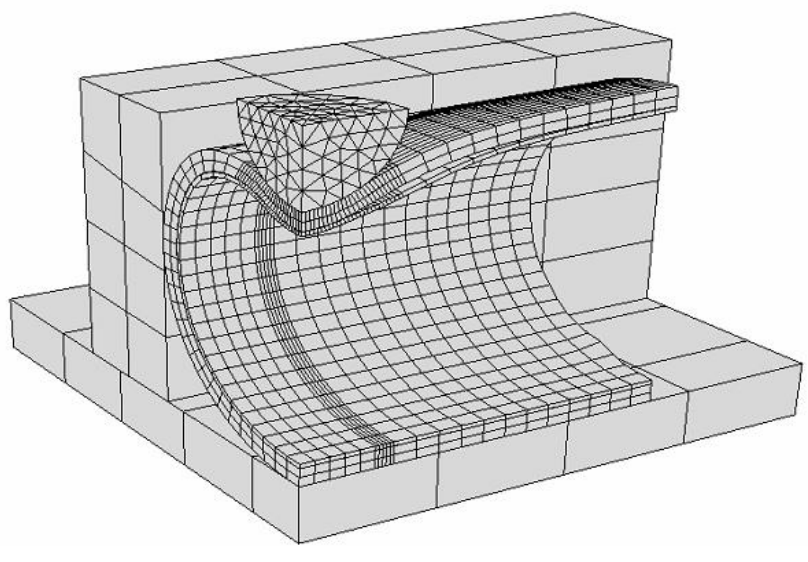

(b)

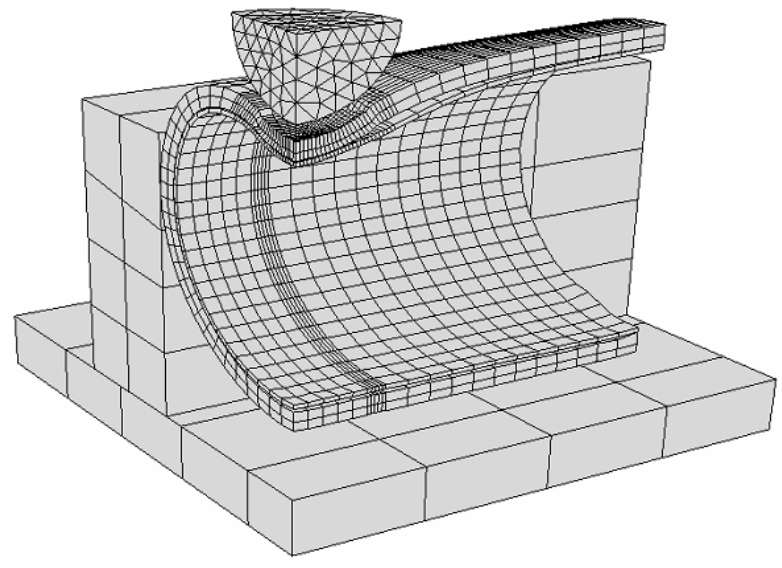

(d)

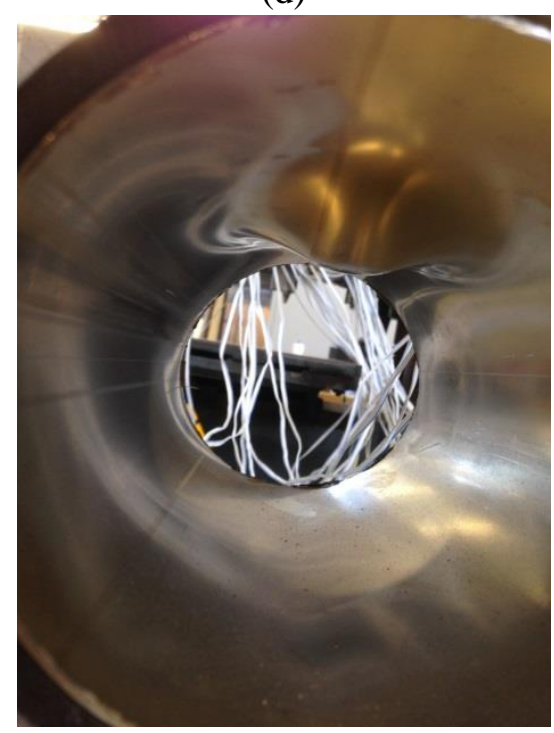

(f)

Fig. 7 The stages of impact from $1 \mathrm{~m}$ high at (a) original position of indenter and lined pipe (un-deformed mesh) at $0 \mathrm{~s}$, (b) deformed shape at $7.5 \mathrm{~ms}$, (c) deformed shape at $75 \mathrm{~ms}$, (d) deformed shape at $250 \mathrm{~ms}$, (e) experimental collision on the outside surface and (f) experimental collision on the inner surface of lined pipe. 
The deformed geometries of the pipe were experimentally obtained with the aid of conventional callipers and a displacement transducer sliding on a greased flat plate perfectly, while the pipe is mounted on V-groove blocks as demonstrated in Fig. 8. These measurements were taken just after completing the test and removing the indenter.

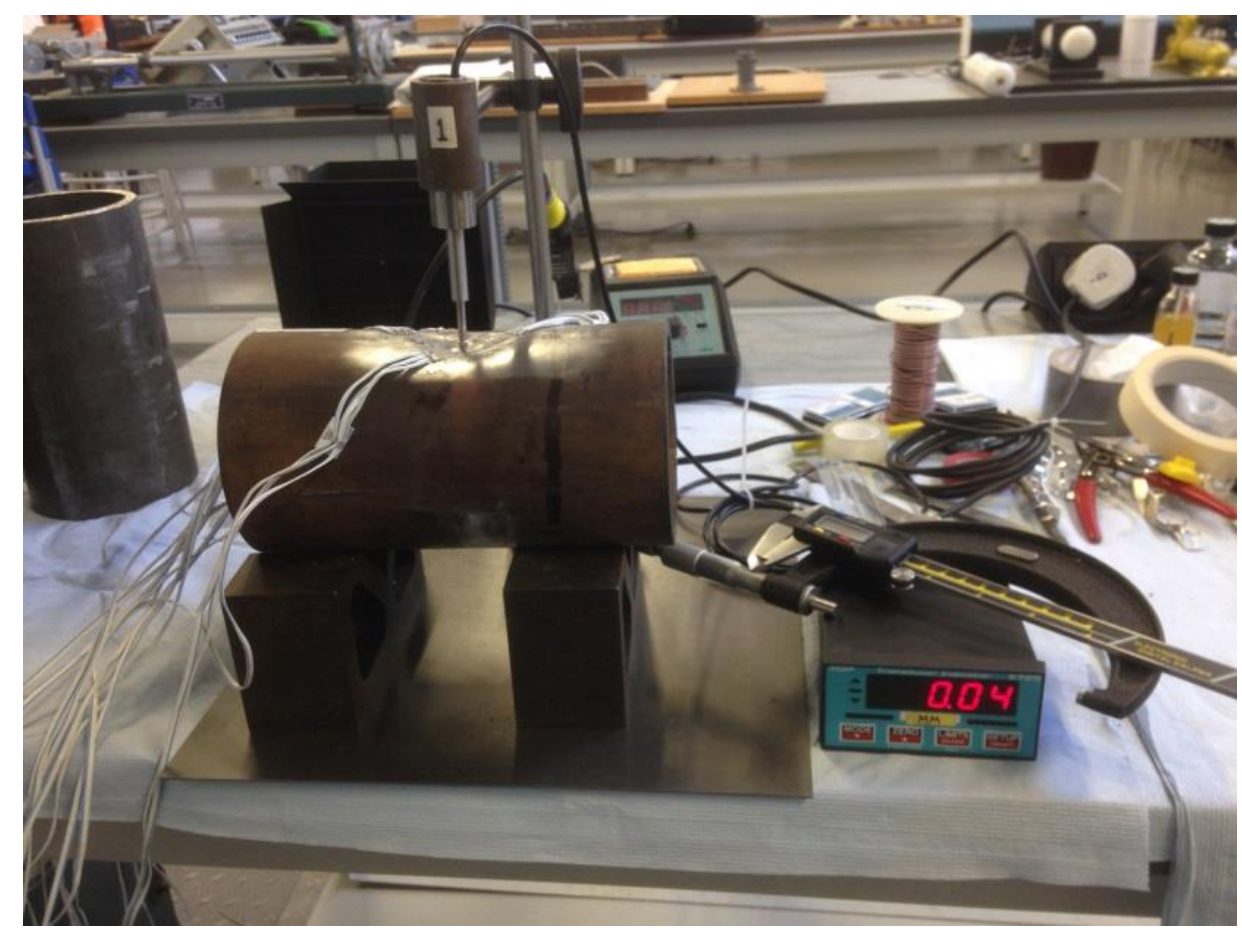

Fig. 8 Experimental set up for pipe geometries.

The deformed geometries resulting from the FE simulations, including the dent depth, are then compared with their counterparts taken experimentally for case A (without liner) and case B (with liner) as reported in Table. 3, where Fig. 9 demonstrates the tabulated deformed geometries of dented pipe. 

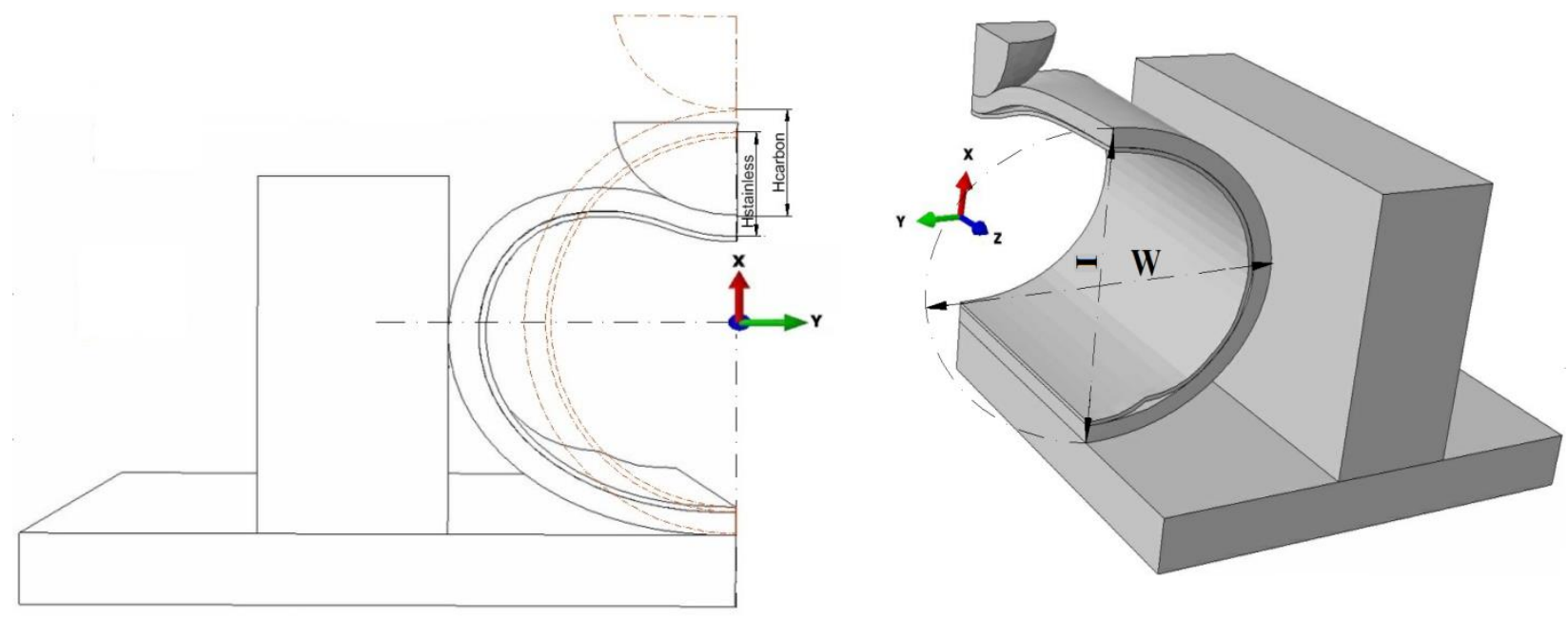

Fig. 9 Deformed geomtries of dented pipe.

Table 3 Numerical and experimental results of pipe geometries including dent depth.

\begin{tabular}{|c|c|c|c|c|c|c|c|c|c|}
\hline \multirow[t]{2}{*}{ Specimen } & \multirow{2}{*}{$\begin{array}{l}\text { Pipe } \\
\text { case }\end{array}$} & \multirow{2}{*}{$\begin{array}{l}\text { Height } \\
\text { (m) }\end{array}$} & & \multirow[t]{2}{*}{$\mathrm{I}(\mathrm{mm})$} & \multirow{2}{*}{$\begin{array}{c}\mathrm{W} \\
(\mathrm{mm})\end{array}$} & \multirow{2}{*}{$\begin{array}{l}\mathrm{H}_{\text {carbon }} \\
(\mathrm{mm})\end{array}$} & \multirow{2}{*}{$\begin{array}{l}H_{\text {stainless }} \\
(\mathrm{mm})\end{array}$} & \multicolumn{2}{|c|}{ H/D \% } \\
\hline & & & & & & & & $\begin{array}{c}\mathrm{C}-\mathrm{Mn} \\
\mathrm{H}_{\text {carbon }} / \mathrm{D}_{\text {carbon }}\end{array}$ & $\begin{array}{c}\text { AISI304 } \\
\mathrm{H}_{\text {stainless }} / \mathrm{D}_{\text {stainless }} \\
\end{array}$ \\
\hline \multirow{2}{*}{ H1A } & \multirow{2}{*}{ A } & \multirow{2}{*}{1} & Exp. & 109.0 & 118.2 & 13.4 & - & 11.7 & - \\
\hline & & & Num. & 109.1 & 118.8 & 14.21 & - & 12.43 & - \\
\hline \multirow{2}{*}{$\mathrm{H} 2 \mathrm{~A}$} & \multirow{2}{*}{ A } & \multirow{2}{*}{1.5} & Exp. & 109.0 & 118.5 & 20.20 & - & 17.67 & - \\
\hline & & & Num. & 109.0 & 118.84 & 20.25 & - & 17.71 & - \\
\hline \multirow{2}{*}{$\mathrm{H} 3 \mathrm{~A}$} & \multirow{2}{*}{ A } & \multirow{2}{*}{2} & Exp. & 108.9 & 119 & 24.5 & - & 21.43 & - \\
\hline & & & Num. & 108.84 & 118.88 & 24.67 & - & 21.58 & - \\
\hline \multirow{2}{*}{ H1B } & \multirow{2}{*}{ B } & \multirow{2}{*}{1} & Exp. & 109.5 & 117.74 & 13.1 & 13.1 & 11.46 & 12.89 \\
\hline & & & Num. & 109.92 & 118.26 & 13.35 & 13.4 & 11.67 & 13.18 \\
\hline \multirow{2}{*}{$\mathrm{H} 2 \mathrm{~B}$} & \multirow{2}{*}{ B } & \multirow{2}{*}{1.5} & Exp. & 109.2 & 118.44 & 18.65 & 18.65 & 16.31 & 18.36 \\
\hline & & & Num. & 109.6 & 118.54 & 18.97 & 18.7 & 16.6 & 18.41 \\
\hline \multirow{2}{*}{$\mathrm{H} 3 \mathrm{~B}$} & \multirow{2}{*}{ B } & \multirow{2}{*}{2} & Exp. & 109.1 & 119 & 22.3 & 22.3 & 19.51 & 21.95 \\
\hline & & & Num. & 109.5 & 118.5 & 23.47 & 23.33 & 20.53 & 22.96 \\
\hline
\end{tabular}

It can be seen from Table 3 that increasing the height of free drop leads to decrease the height of deformed pipe end, I, in the cases without liner, H1A, H2A and H3A, and with liner, H1B, $\mathrm{H} 2 \mathrm{~B}$ and $\mathrm{H} 3 \mathrm{~B}$, numerically and experimentally. The reduction in the height of end pipe (from $114.3 \mathrm{~mm}$ ) in the cases without liner is relatively larger corresponding to their counterparts with liner. In the opposite direction, increasing the height of the free drop pushes the deformed pipe width, W, outward (from $114.3 \mathrm{~mm}$ ) in all cases. The deformed pipe width in the cases without liner relatively is larger than their corresponding cases with liner. As a result, the dent depth of the outer pipe, $\mathrm{H}_{\text {carbon }}$, in the cases without liner is deeper than their corresponding cases with liner. Thus, the ratio of dent depth-to-carbon pipe outer diameter, 
$\mathrm{H}_{\text {carbon }} / \mathrm{D}_{\text {carbon }}$, in the cases without liner is numerically and experimentally larger than their counterparts with liner. Furthermore, in the lined cases, the ratio of dent depth-to-stainless steel pipe outer diameter, $\mathrm{H}_{\text {stainless }} / \mathrm{D}_{\text {stainless }}$, is larger than corresponding ratio of the outer pipe, $\mathrm{H}_{\text {carbon }} / \mathrm{D}_{\text {carbon, as schematically sketched in Fig. } 9 .}$

The European Pipeline Research Group (EPRG) has found out that the pipe with a smooth dent (plain dent) in the non-pressurized condition does not fail in two cases [17]. The first condition is that the internal pressure is less than the maximum operating pressure (MOP) which is calculated as that corresponding to the stress given by $72 \%$ of the specified minimum yield stress (SMYS). The second one is that the dent depth is equal or less than $10 \%$ of the pipe outside diameter. In our study, in all cases pipes are dented under nonpressurized condition. Furthermore, all cases firmly have ratios of dent depth-to-pipe outer diameter greater than $10 \%$ which will lead to failure in the pipe in service according to EPRG. Increasing the height of free drop drives to an increase in the ratio relatively. In this work, $200 \mathrm{~kg}$ freely drops from $1 \mathrm{~m}$ high is the minimum weight and height, respectively, to get a critical situation to the lined pipes used with the same size in Oil \& Gas industry.

In case that the pipe is dented in the pressurised condition, the dent is pushed outwards by the internal pressure. As a result, the dent depth in a pressurised pipe is less than that in a nonpressurised pipe. According to EPRG, the correlated ratio between dent depth in nonpressurised pipe to that in pressurised pipe is 1.43 . Therefore, the minimum ratio of dent depth-to-pipe outer diameter to get failure in pressurised pipe is $7 \%[17,18]$.

\subsection{Strain behaviour in the dented region}

In this work, the main aim is to study the strain and stress behaviour in the dented region by comparing the numerical predictions with the experimental strain results recorded during the impact test. With this aim, four groups of strain gauges were mounted on the external surface of C-Mn. First and second group, GR1 and GR2, were located on the longitudinal plane with positions given by $\phi=0^{\circ}$ and $\mathrm{Z}= \pm 23 \mathrm{~mm}$. The last two groups of strain gauges, GR3 and GR4, were placed on the transverse plane with locations of $\phi= \pm 23.7^{\circ}$ and $\mathrm{Z}=0 \mathrm{~mm}$ as sketched in Fig. 10. 


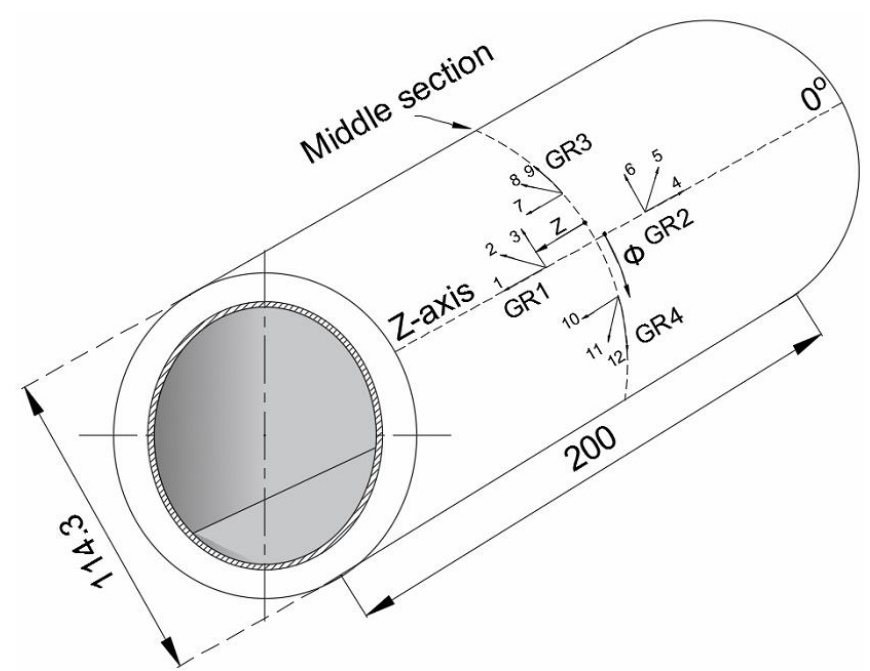

Fig. 10 positions of the strain gauges, dimensions in $\mathrm{mm}$.

Those locations kept the strain gauges safe from damage by punching from possible damage caused by the indenter. Moreover, the levels of strain in these positions are suitable to the maximum limit of strain in the gauges. The closer the distance to the dent centre, the larger the strain levels. Therefore, the suitable position for the gauges was identified based on the results of numerical models.

During the impact test, the signals from the strain gauges were recorded by a computer based data acquisition system run via LabVIEW code. Each group contained at least two strain gauges (biaxial strain gauges) where one gauge (element) measured the axial strain and the other one measured the hoop strain. Some gauges were tri-axial, known as 3-axis rosette gauge, but the diagonal strain with $45^{\circ}$ in XY-plane was found to record significantly lower strain values compared to the axial and hoop strain values. However, the experimental results of longitudinal strain gauge groups, GR1 and GR2, were almost identical and also the transversal strain gauge groups had the same results. The symmetric-plane strain groups were used to double check the reliability of experimental results and also to record strains from at least one gauge in case one of the gauges was damaged or detached by the impact.

To sum up, the experimental results recorded from GR1, located on the longitudinal plane, and from GR4, located on the transverse plane, have been compared with the numerical results located at the same positions on the quarter pipe FE model. Figs. 11 and 12 show these comparisons in case A and case B, respectively. As mentioned earlier, the indenter and the pipe collided many times during one impact process before the indenter settled over the pipe in all cases (with and without liner). The most severe collision was obviously the first one in the impact process, when significant plastic deformation occurred in the dented region. 


\subsection{1. $\quad$ Strain behaviour in case A (without liner)}

Fig. 11(a) shows the axial and hoop strains generated by GR1 rosette on the C-Mn pipe without liner (H1A specimen), where the free drop height is $1 \mathrm{~m}$. The FEA results in the same location of GR1 are also plotted in the same figure. GR1 rosette is positioned on the longitudinal plane at $\mathrm{Z}=23 \mathrm{~mm}$ from the dent centre. The numerical time is synchronised with the experimental time, assuming time to be zero when the tip of indenter touches the external surface of pipe. The hoop strain gauge records compressive mechanical strains reaching a maximum of $-8.12 \%$ after $7.5 \mathrm{~ms}$ of striking. After that, the strains reduce in the pipe due to the so-called 'spring back', because the indenter with weight block rebounds vertically away from the pipe. The strain then reaches a steady-state with $-7.4 \%$ as residual plastic strain. Consequently, $0.72 \%$ of the initially compressive strain was elastic strain. On the axial direction, the gauge records a tensile strain history in which the peak tensile strain reaches a steady-state value of $5 \%$ after $7.5 \mathrm{~ms}$.

Upon free drop of the weight from $1 \mathrm{~m}$ over the H1A specimen, GR4 rosette records the strain history on the transverse plane. It is positioned with clockwise circumferential angle $\phi$ $=23.7^{\circ}$ far from the dent centre. Like the GR1 rosette, the GR4 rosette measures the strain history at axial and hoop direction. In contrast to GR1, axial strain gauge records compressive strain whereas hoop one records tensile strain. It is clear from Fig. 11(b) there is also a convex kink in the compressive strain curve at $7.5 \mathrm{~ms}$ from the onset of strike where the dent reaches its maximum depth. After that, the spring back phenomenon dominates in the dent region when the hitting tool rebounds away from the C-Mn pipe to keep the compressive strain steady-state curve. It is also observed that there is no protruding kink in the positive hoop strain curve. One may note from Fig. 11(a) and (b) that the absolute values of compressive strains are larger than those of tensile strains. Furthermore, the absolute values of compressive and tensile strains on the longitudinal plane, Fig. 11(a), are larger than their counterparts on the transverse plane, Fig. 11(b). It is also noticeable in specimen H1A that the tangent strains to the periphery of the dent are compressive whereas their perpendicular counterparts are always positive [19]. In more detail, the gauge on the longitudinal plane, GR1 records a tensile strain in the axial direction whilst the gauge on the transverse plane, GR4, records a compressive strain in the axial direction.

In case of dropping $200 \mathrm{~kg}$ freely from $1.5 \mathrm{~m}$ over $\mathrm{H} 2 \mathrm{~A}$ specimen, the absolute values of strains in GR1 and GR4 rosettes are larger than their counterparts in the H1A specimen. Fig. 
11(c) shows that the steady state of axial strain in GR1 after the first strike is $7.4 \%$ whereas its counterpart in H1A specimen is 5\%. Moreover, Fig. 11(d) clarifies that the maximum tensile hoop strain reaches $3 \%$ strain while its counterpart in H1A specimen reaches just $2.45 \%$ strain. In a similar way, it can be seen from Fig. 11(e) and (f) that extending the free drop height up to $2 \mathrm{~m}$ over $\mathrm{H} 3 \mathrm{~A}$ specimen leads to increase the absolute values of recorded and predicted strains in GR1 and GR4 comparing to those in cases H1A and H2A accordingly.

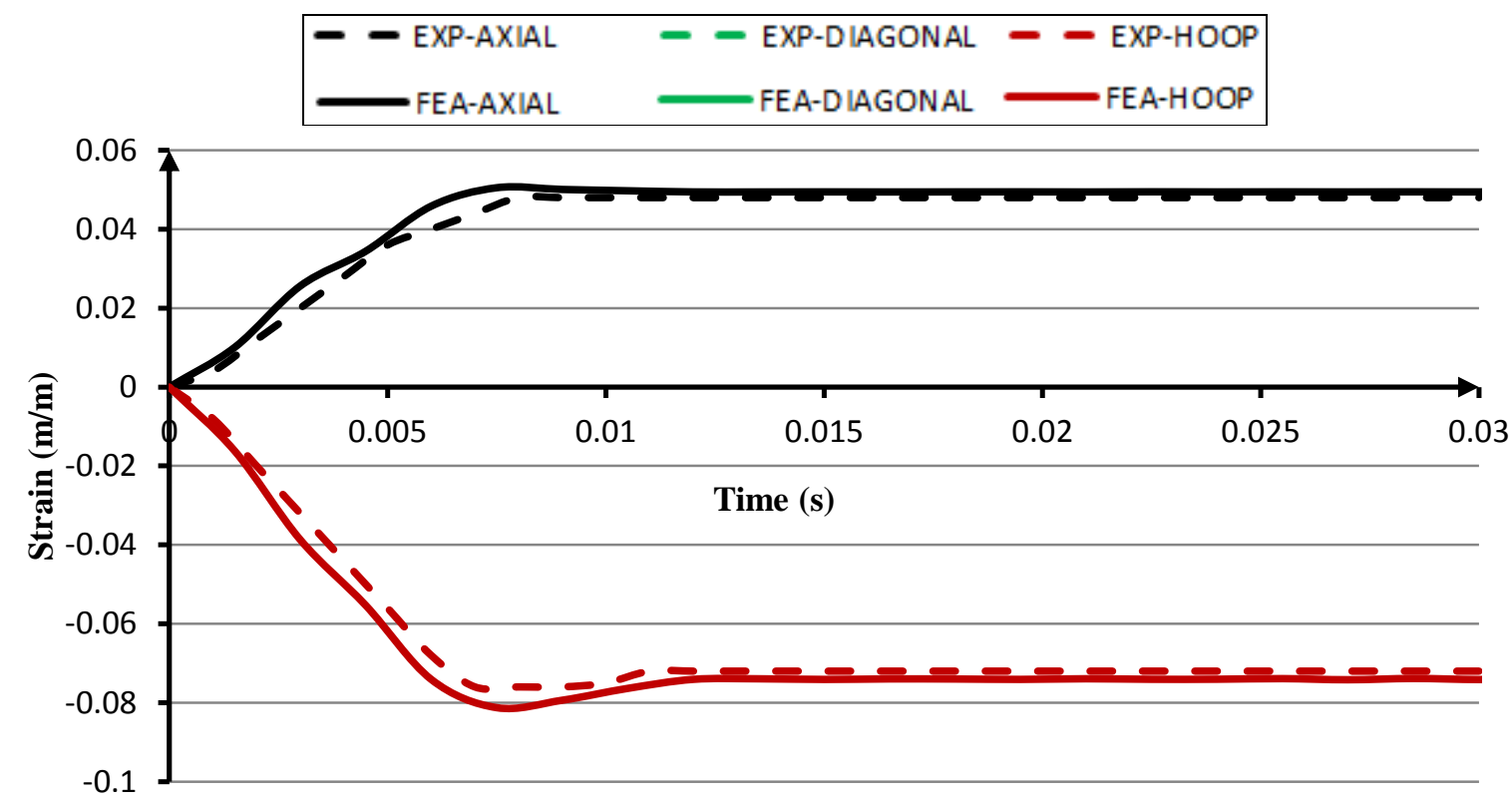

(a)

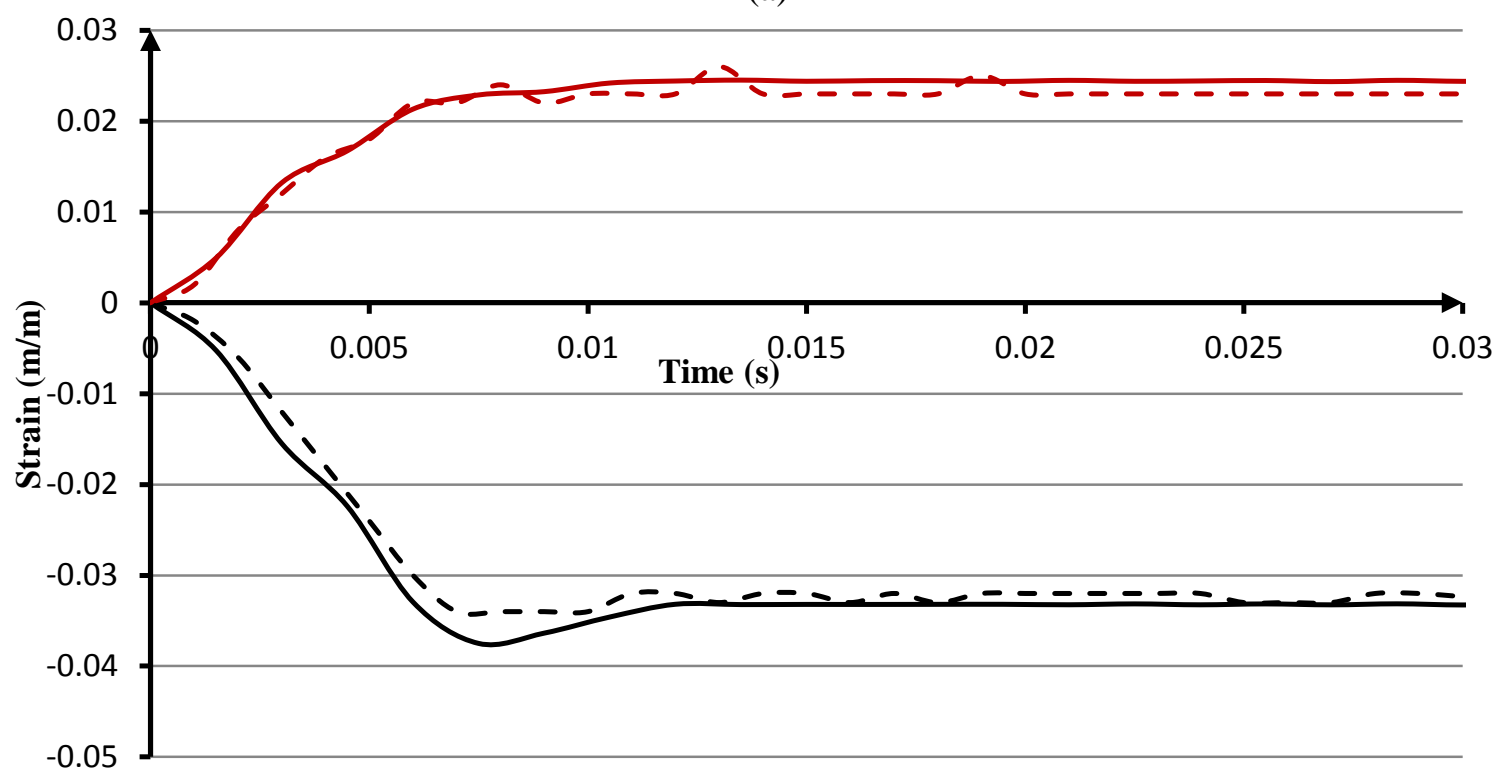

(b) 


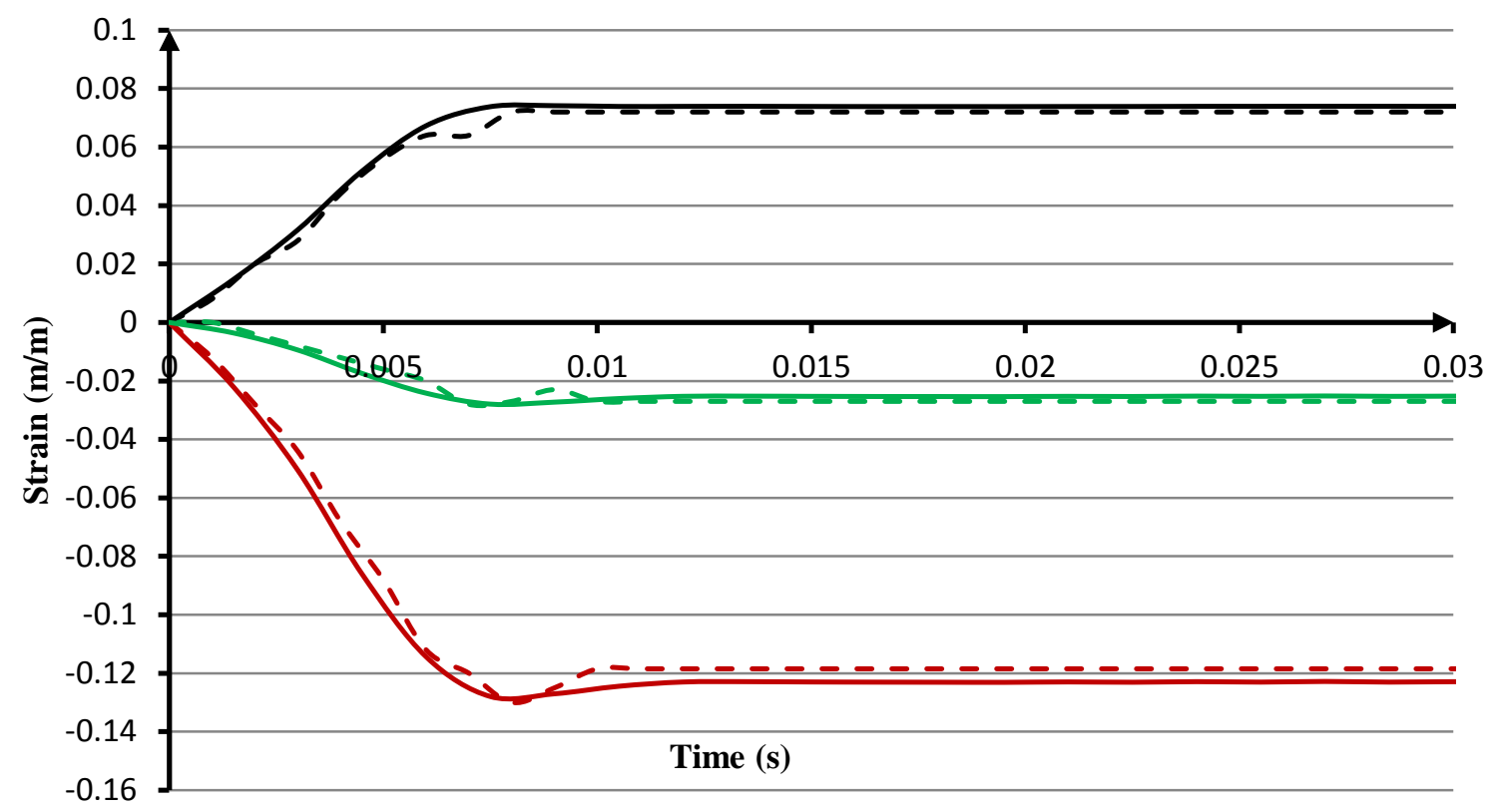

(c)

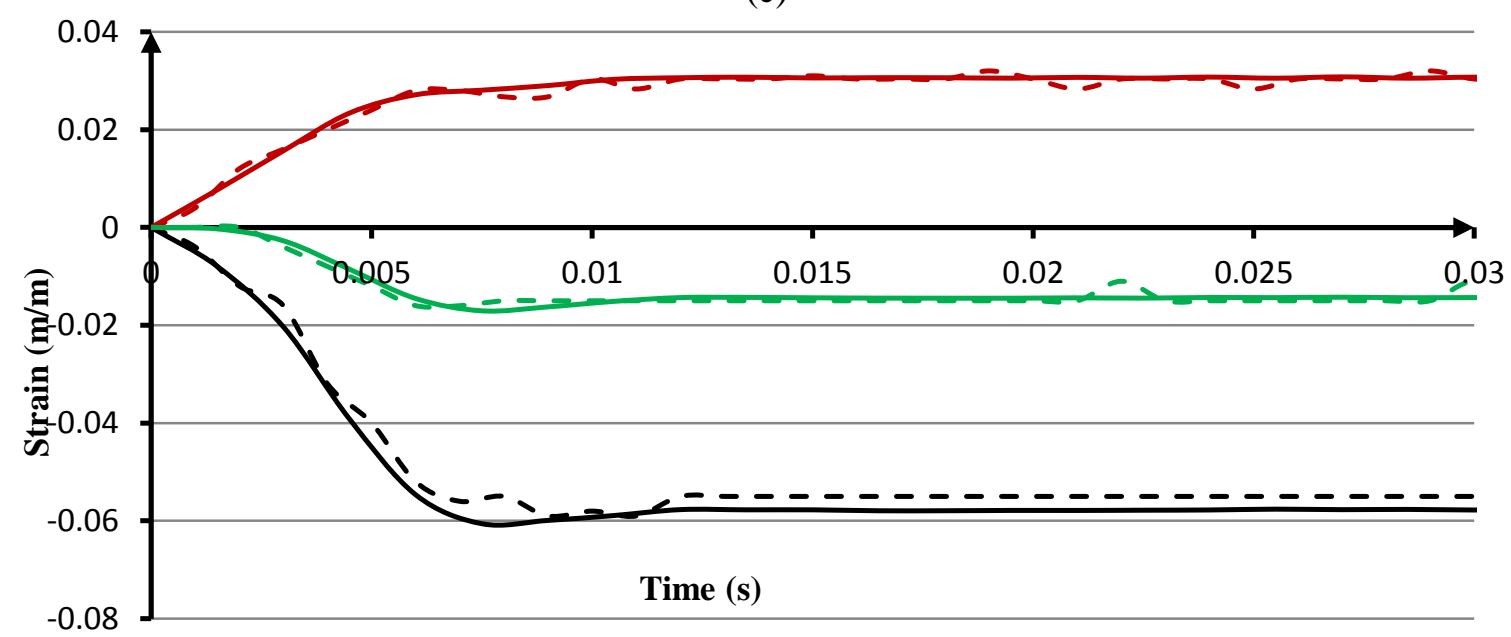

(d)

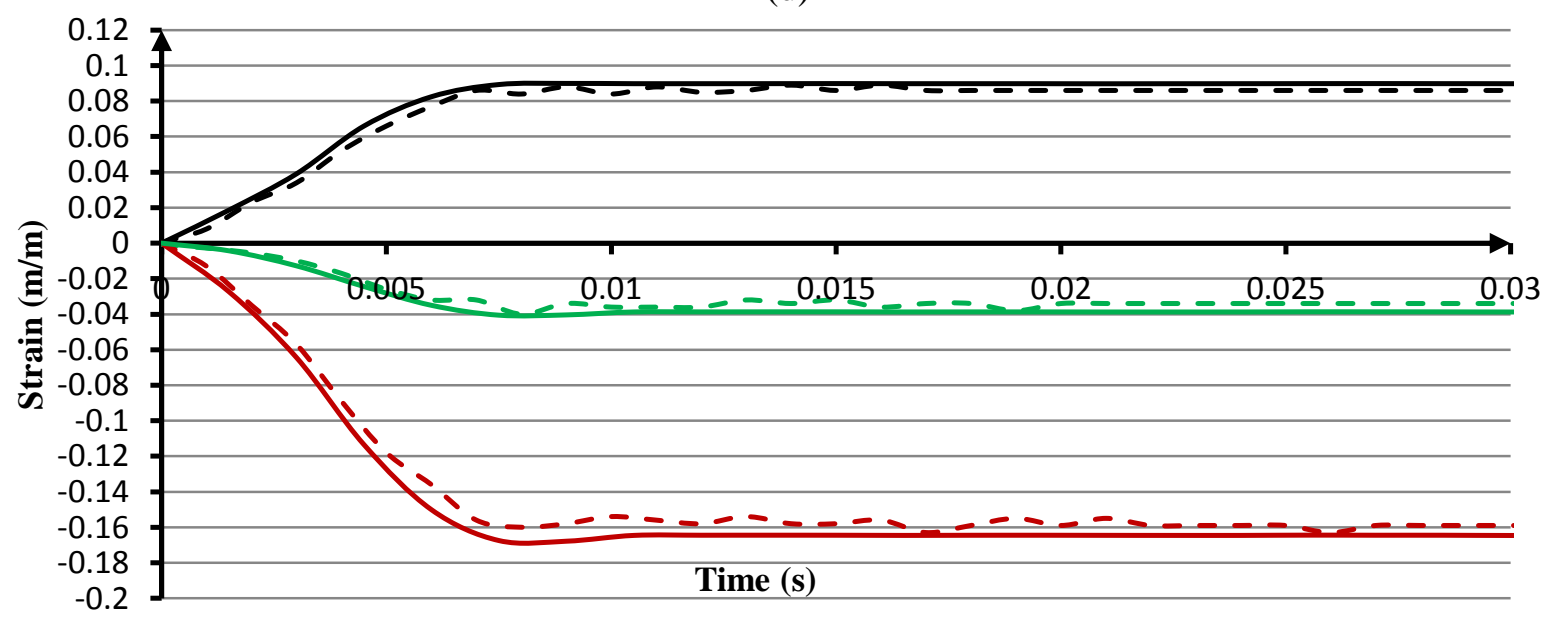

(e) 


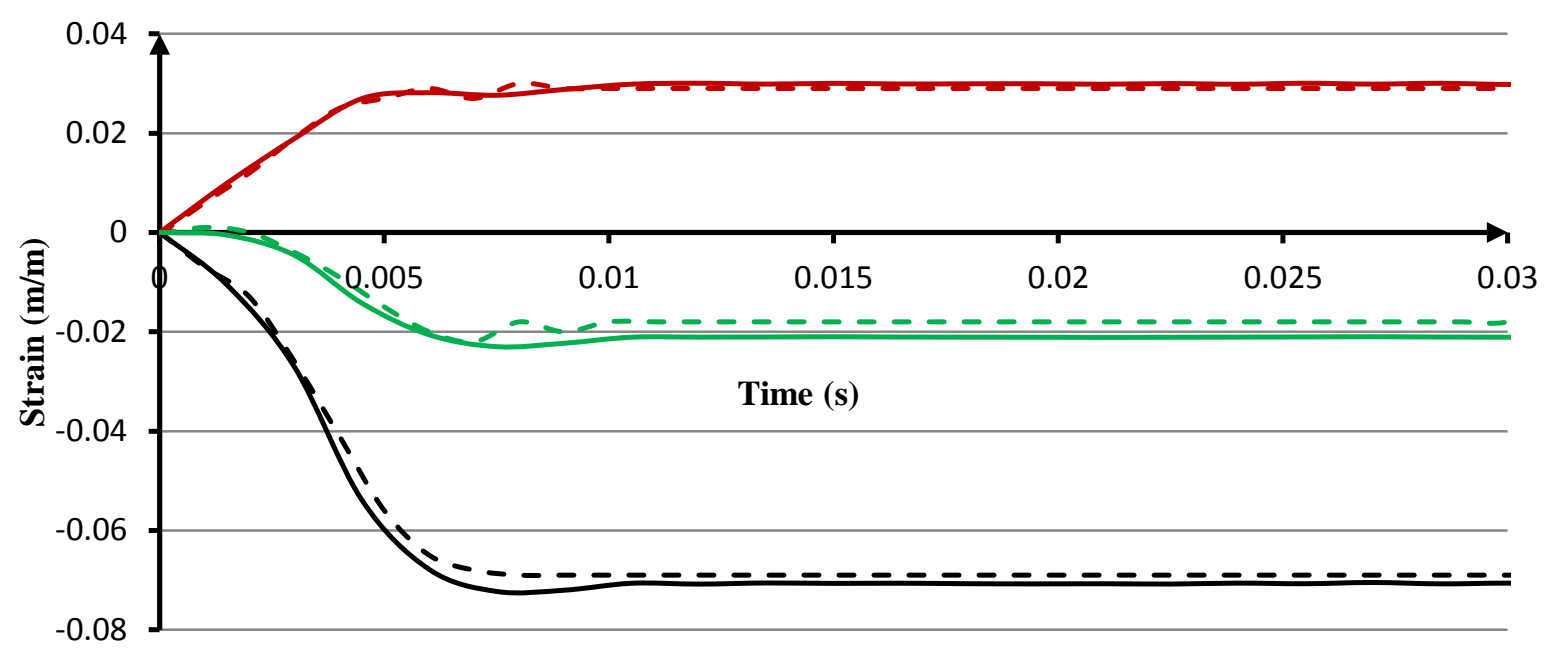

(f)

Fig. 11 strain histories in Rosette (a) GR1 (H1A), (b) GR4 (H1A), (c) GR1 (H2A), (d) GR4 (H2A), (e) GR1 (H3A), (f) GR4 (H3A).

\subsection{2. $\quad$ Strain behaviour in case B (with liner)}

The same foregoing discussion of case A specimens applies to the corresponding case B specimens as shown in Fig. 12 (a)-(f). It is observed that the absolute values of the strains in cases A are larger than their counterparts in cases B. It can be also observed that strains which are tangent to the dent periphery (hoop and axial strains in GR1 and GR4, respectively) are always compressive whereas their orthogonal counterparts (axial and hoop strains in GR1 and GR4, respectively) are always tensile. Furthermore, increasing the free drop height leads to increase the absolute values of numerical and measured strains in gauges GR1 and GR4. In all cases, A and B, the numerical results are consistent well with the experimental ones. 


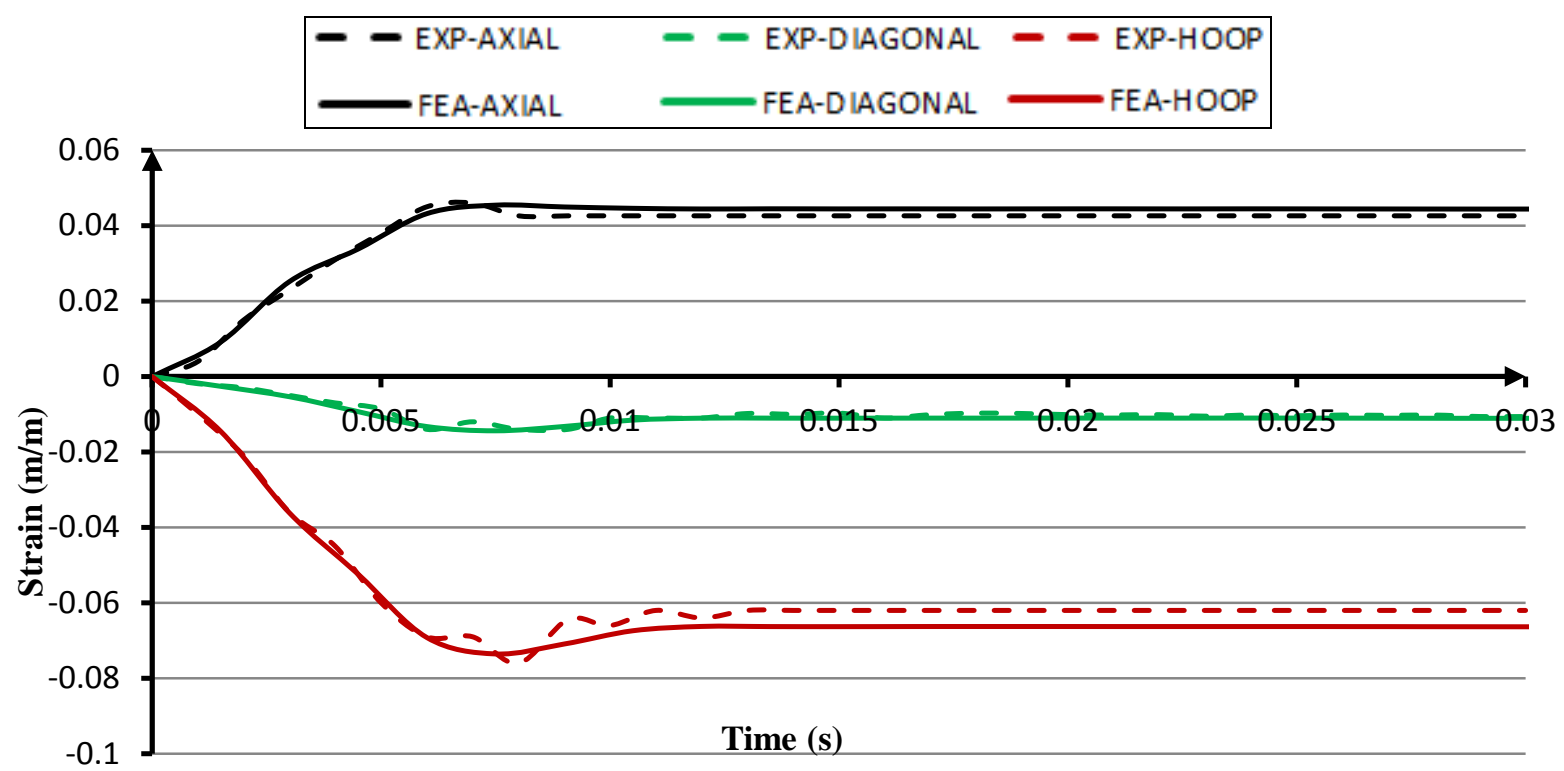

(a)

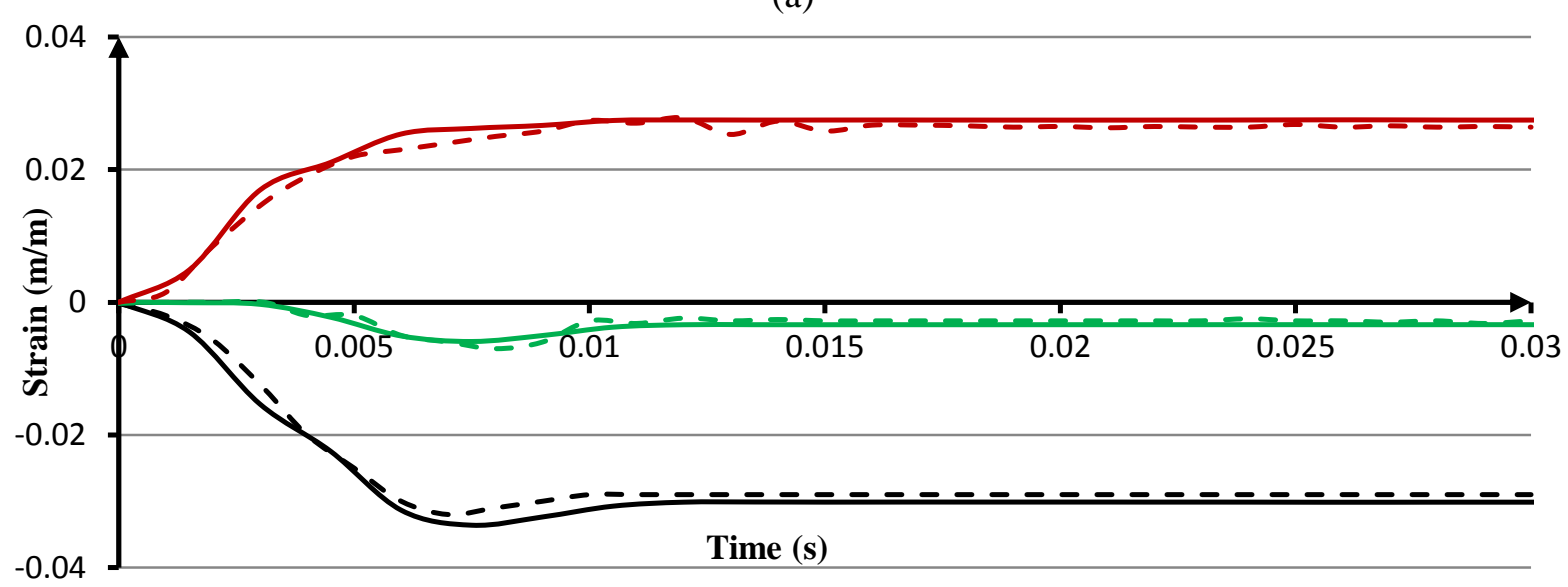

(b)

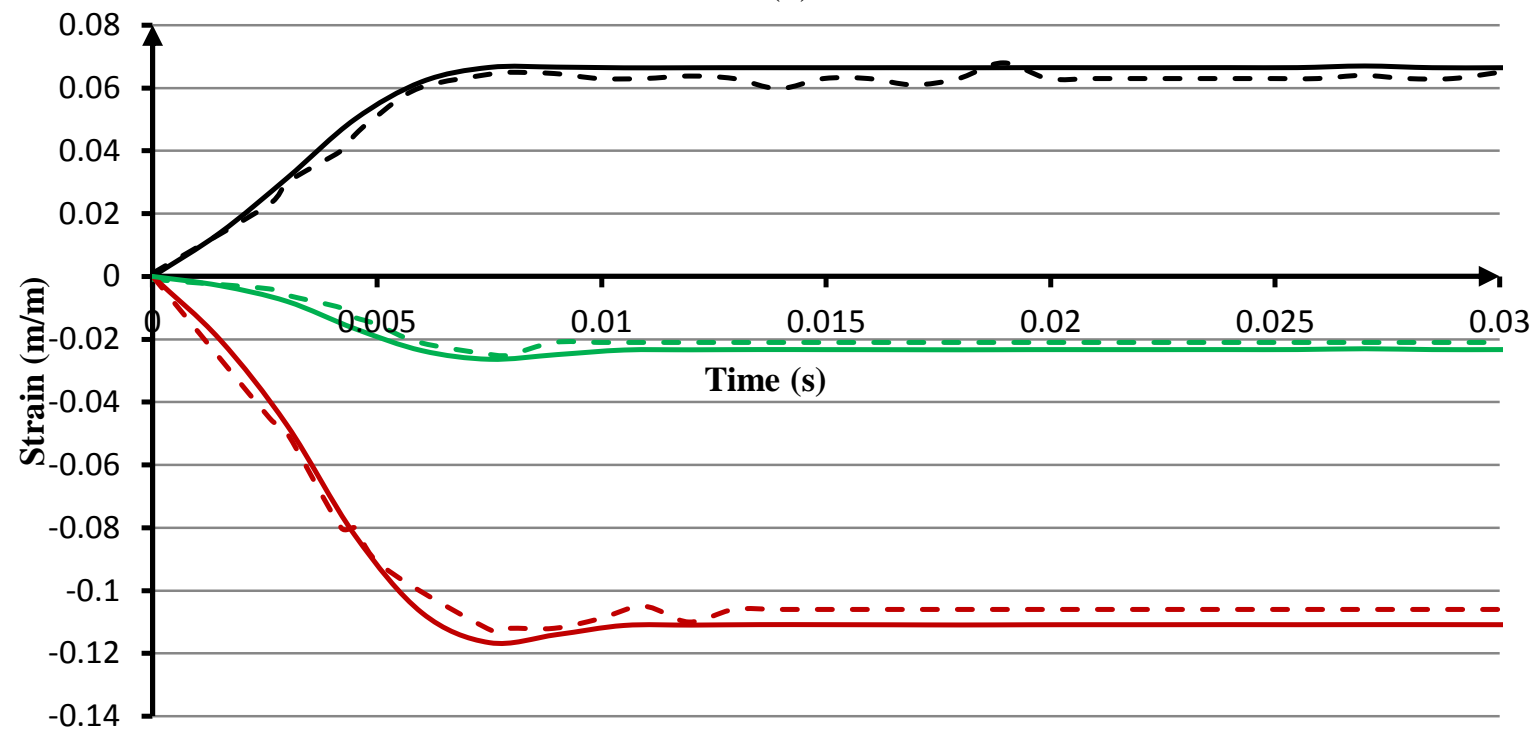

(c) 


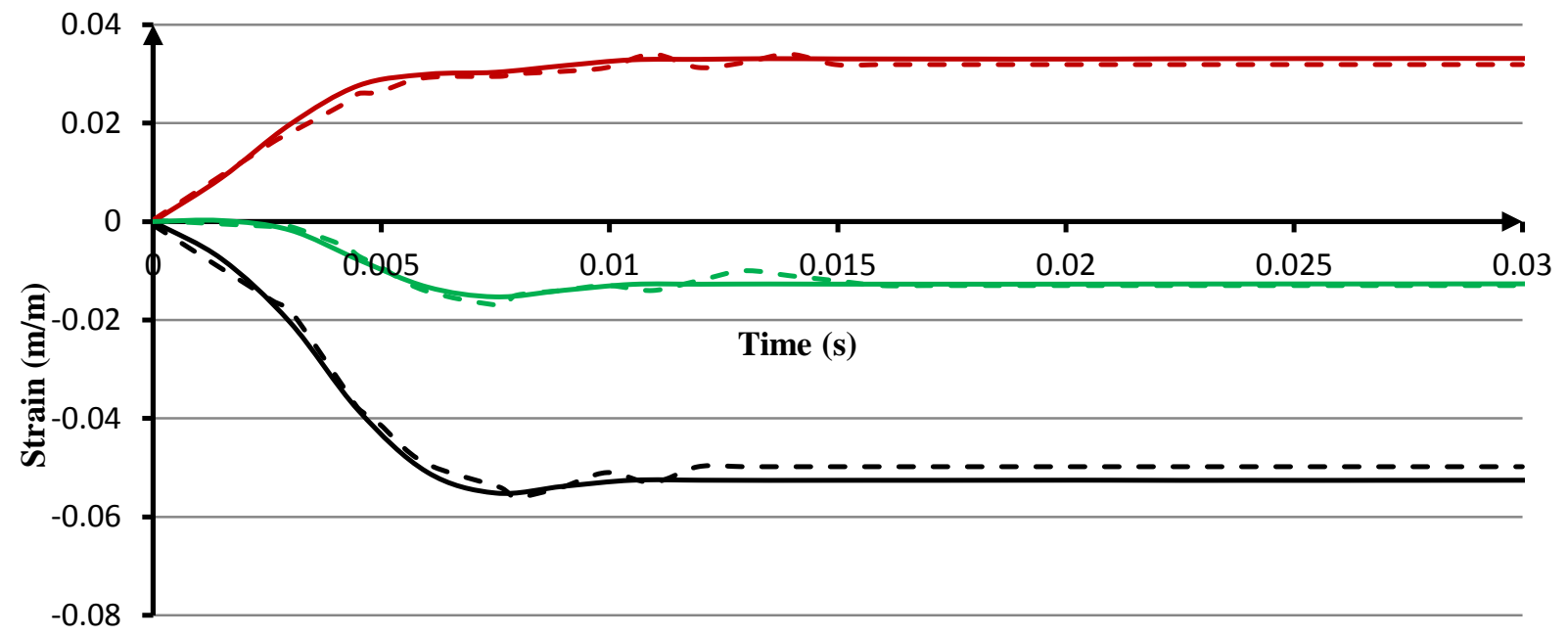

(d)

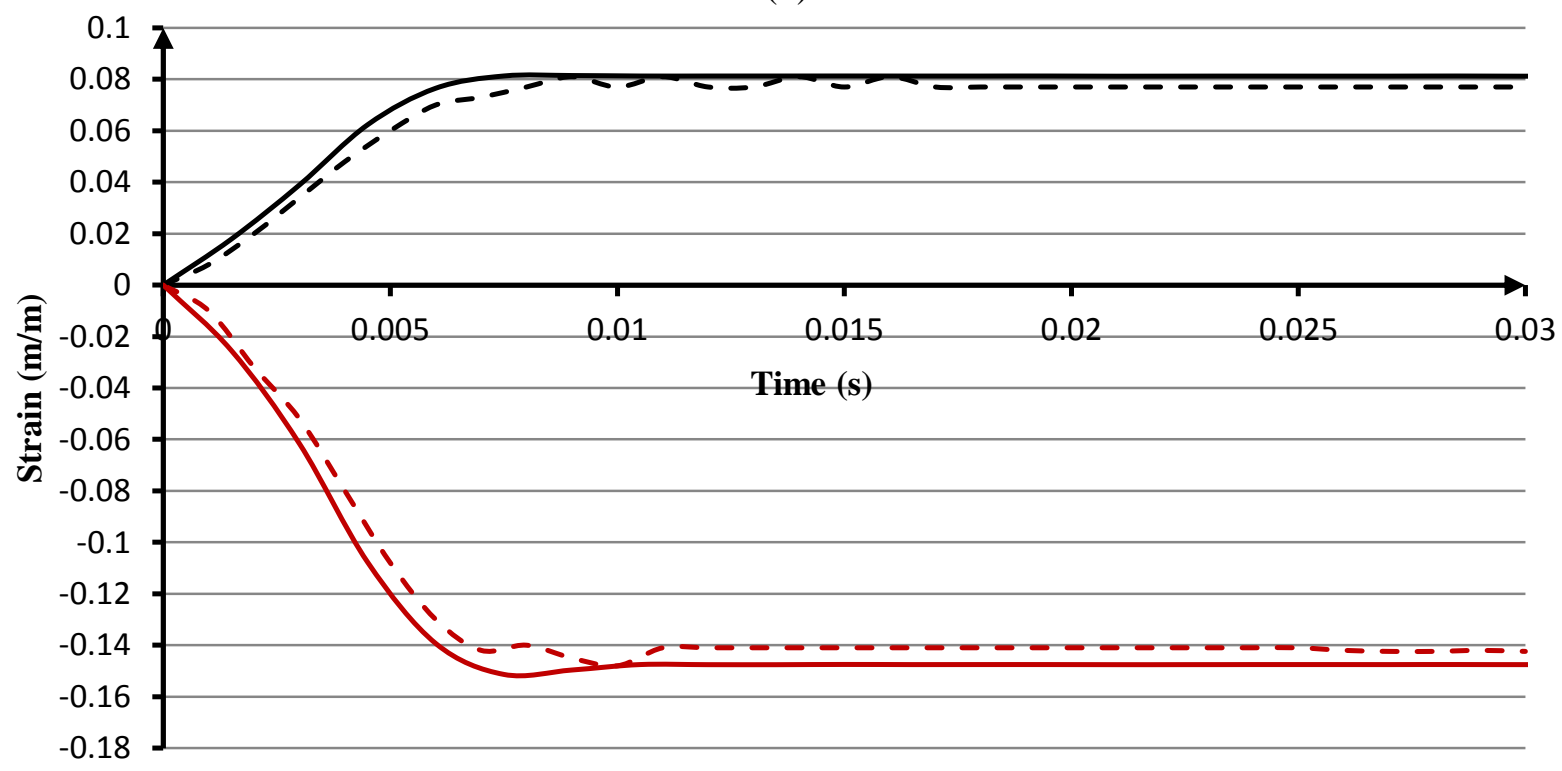

(e)

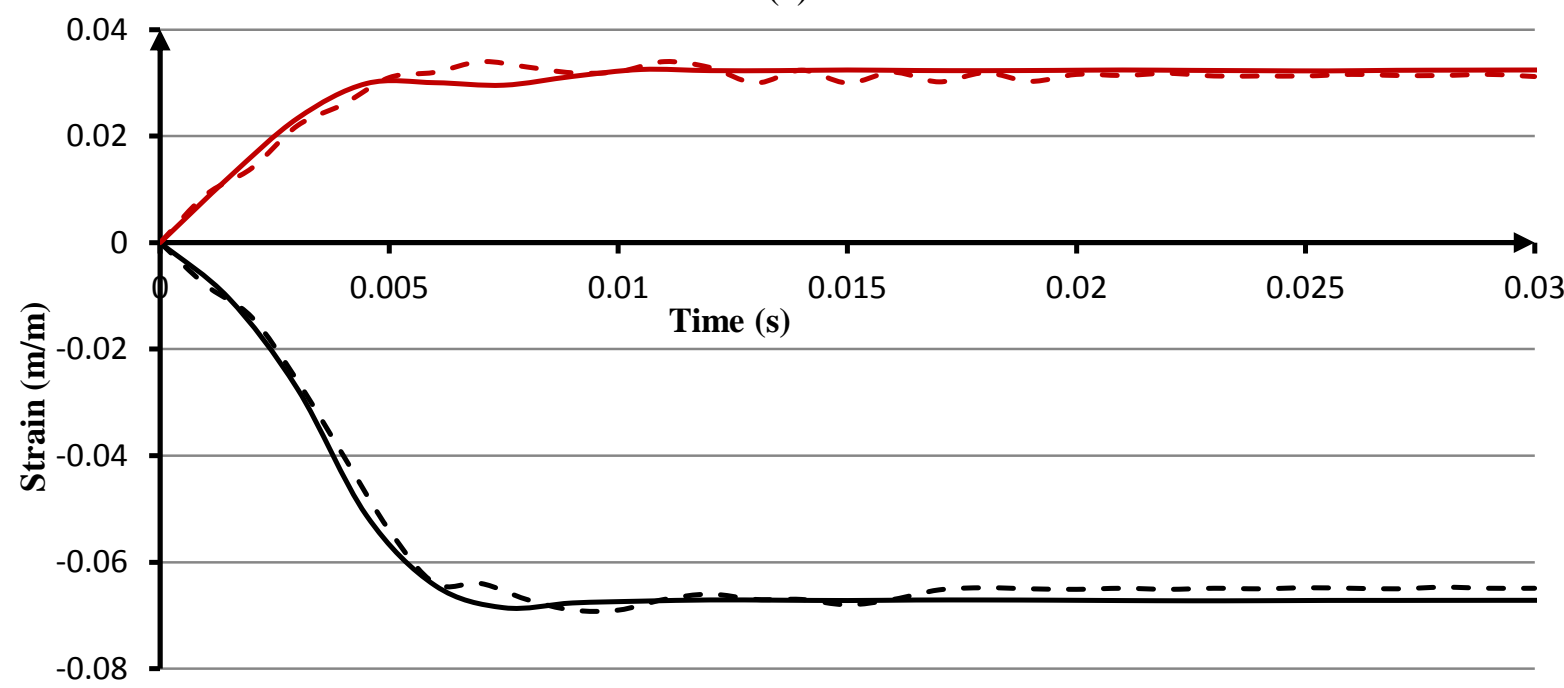

(f)

Fig. 12 strain histories in Rosette (a) GR1 (H1B), (b) GR4 (H1B), (c) GR1 (H2B), (d) GR4 (H2B), (e) GR1 (H3B) and (f) GR4 (H3B). 


\subsection{Residual stresses}

Good correlation between experimental results and numerical results in terms of deformed geometries and strains led us to study the residual stresses numerically with sufficient confidence. For all simulations, the initial load step for impact simulation was 2 seconds with a subsequent load step of 1 second for the dent spring back and achieving final deformed shape of the dent.

According to ASME B31.4 [20], a smooth dent in liquid pipelines with a dent depth-to-pipe diameter ratio (H/D) exceeding 6\% should be repaired when the hoop stress levels are over $20 \%$ of the SMYS. In a similar way, for gas pipelines, ASME B31.8 [21] states that repair is required when the ratio (H/D) exceeds $2 \%$ and hoop stress levels exceed $40 \%$ of the SMYS. In this work, all cases with liner or without liner have a ratio of H/D over $10 \%$ as reported in Table 3. As a result, hoop stress levels in the dented pipe play a significant role in making a decision regarding repair work [22]. To shed light more on the residual stress behaviour, specimen H1B is chosen to analyse the Von Mises stress distributions in the dented region on different surfaces after completing the impact process (spring back) as depicted in Fig. 13. It is observed that the maximum residual stress concentration is located at the dent periphery on the outer surface, not in the dent centre [23]. Consequently, the outer surface of C-Mn pipe in all cases is more prone to crack initiation and propagation especially if the dent is located on a girth weld.

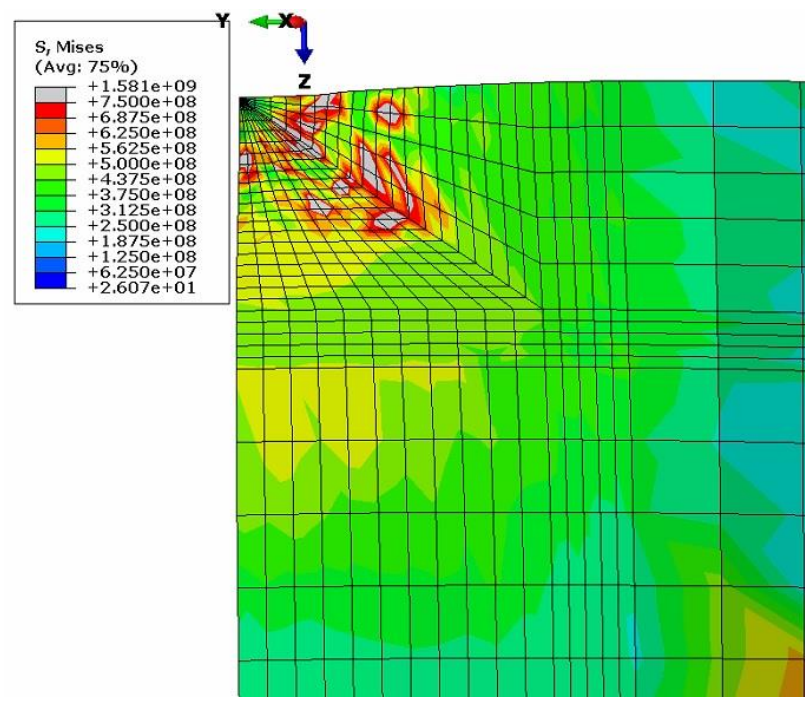

(a)

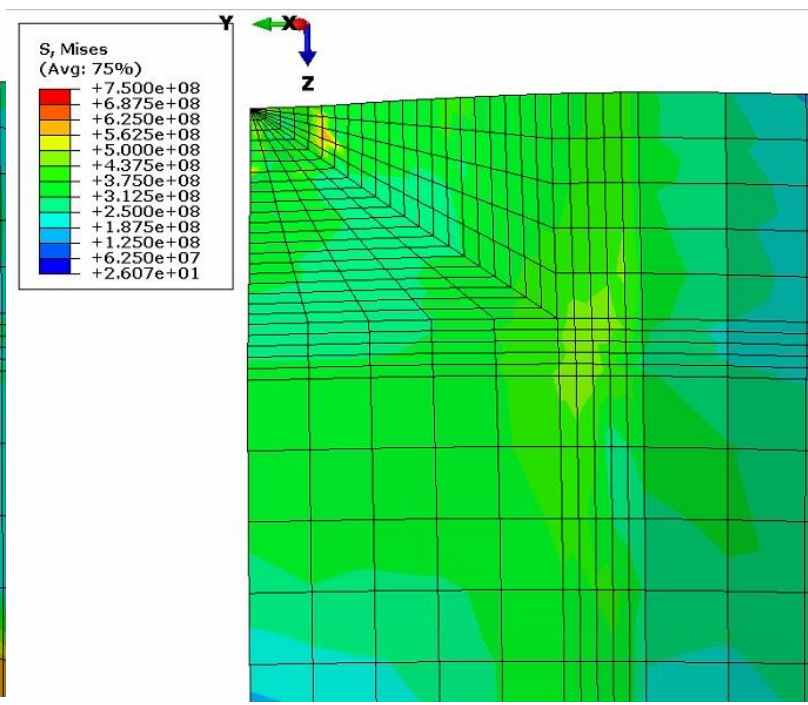

(c) 


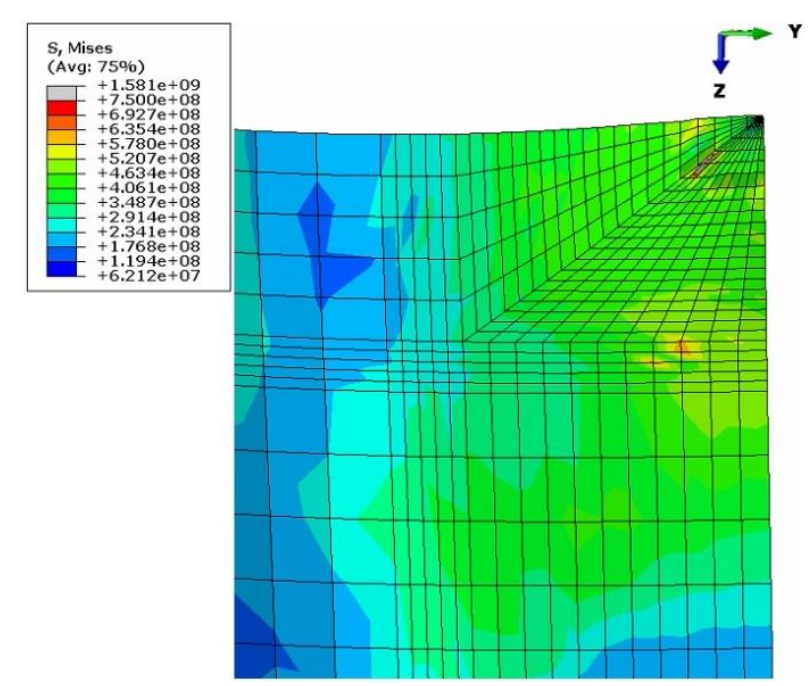

(b)

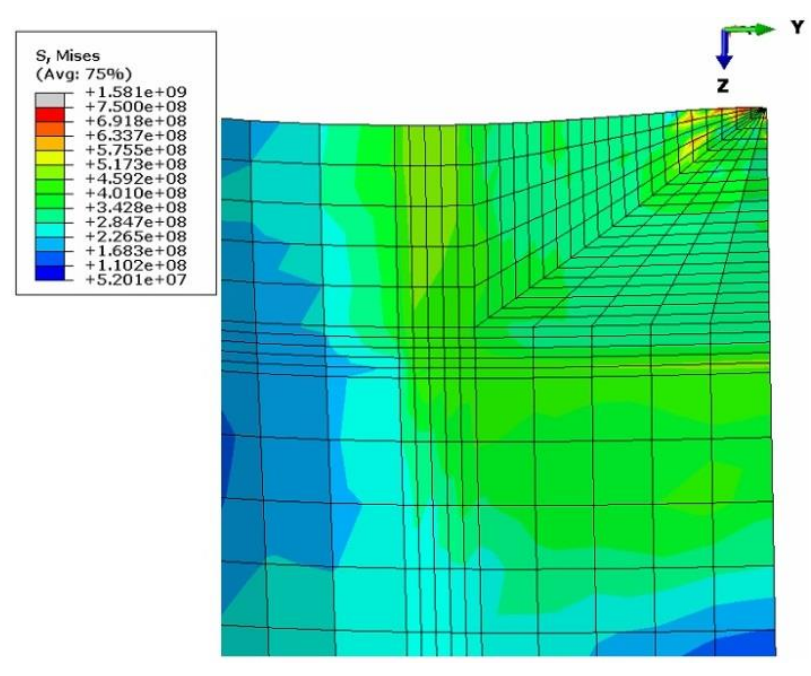

(d)

Fig. 13 Residual Von Mises stresses in the dented region of H1B specimen on the (a) top surface of C-Mn pipe (b) bottom surface of C-Mn pipe (c) top surface of AISI304 pipe (d) bottom surface of AISI304 pipe.

As for the residual stress distributions on the outer surface, the hoop stresses have larger magnitudes of tensile stresses than axial stresses. As a matter of fact, the hoop stress is theoretically twice the axial stress in the pressurized pipe in service. Therefore, the hoop residual stresses should be considered more important when studying the stress behaviour in the dented region. In this section, the hoop residual stress distributions in the longitudinal and transverse planes starting from the dent centre have been investigated. Fig. 14 shows the hoop residual stresses at the longitudinal and transverse planes on the outer surface for case A (without liner) and case B (with liner).

It is observed from Fig. 14(a)-(d) that increasing the drop height leads to reducing the maximum tensile residual stresses, probably because the equivalent plastic strain rate plays a vital role. In particular, increasing the equivalent plastic strain rate highly increases the yield stress of material [24]. Furthermore, the maximum tensile residual stresses are located on the periphery of the dent. Increasing the drop height leads also to expanding the dent diameter which in turns pushes the maximum tensile stresses farther away from the dent centre.

On the longitudinal direction, it could be seen from the comparison between Fig. 14(a) and (b) that the maximum tensile stresses in case A (without liner) are lower than their counterparts in case B (with liner). In more detail, the maximum tensile stresses in cases H1A and $\mathrm{H} 1 \mathrm{~B}$ associated with the free dropping of the weight from $1 \mathrm{~m}$ are 380 and $496 \mathrm{MPa}$, respectively. This can be attributed to the accumulation of residual stresses because of the sequential strikes in each impact process where the indenter hits the pipe with different 
velocity in each strike. For example, the velocity in the second sequential strike in case H1B is lower than its counterpart in case H1A because of the dissipation of internal energy which is, for example, increased by $3 \%$ in case H1B compared to its counterpart in case H1A when forming the maximum dent depth in the first strike. Dissipation of energy and impact velocity are discussed later in next sections.

On the transverse direction, it is noticeable from Fig. 14(c) and (d) that the maximum tensile stresses in cases A and B are lower than their counterparts on the longitudinal direction. In detail, the maximum tensile residual stress along the longitudinal direction of case H1B is $496 \mathrm{MPa}$ whereas the maximum one around the transverse direction of case H1B is $352 \mathrm{MPa}$. In a similar way, the maximum tensile stresses in case $\mathrm{A}$ are somewhat lower than their counterparts in case B.

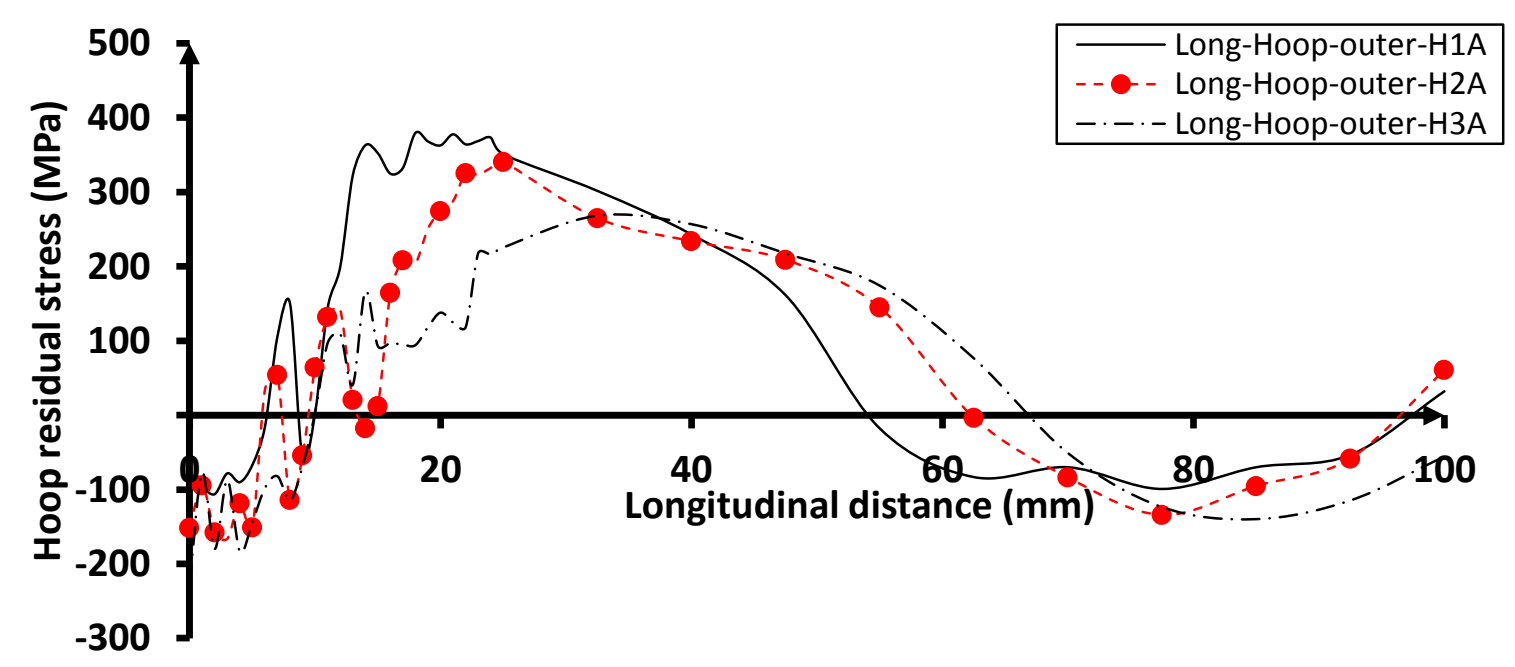

(a)

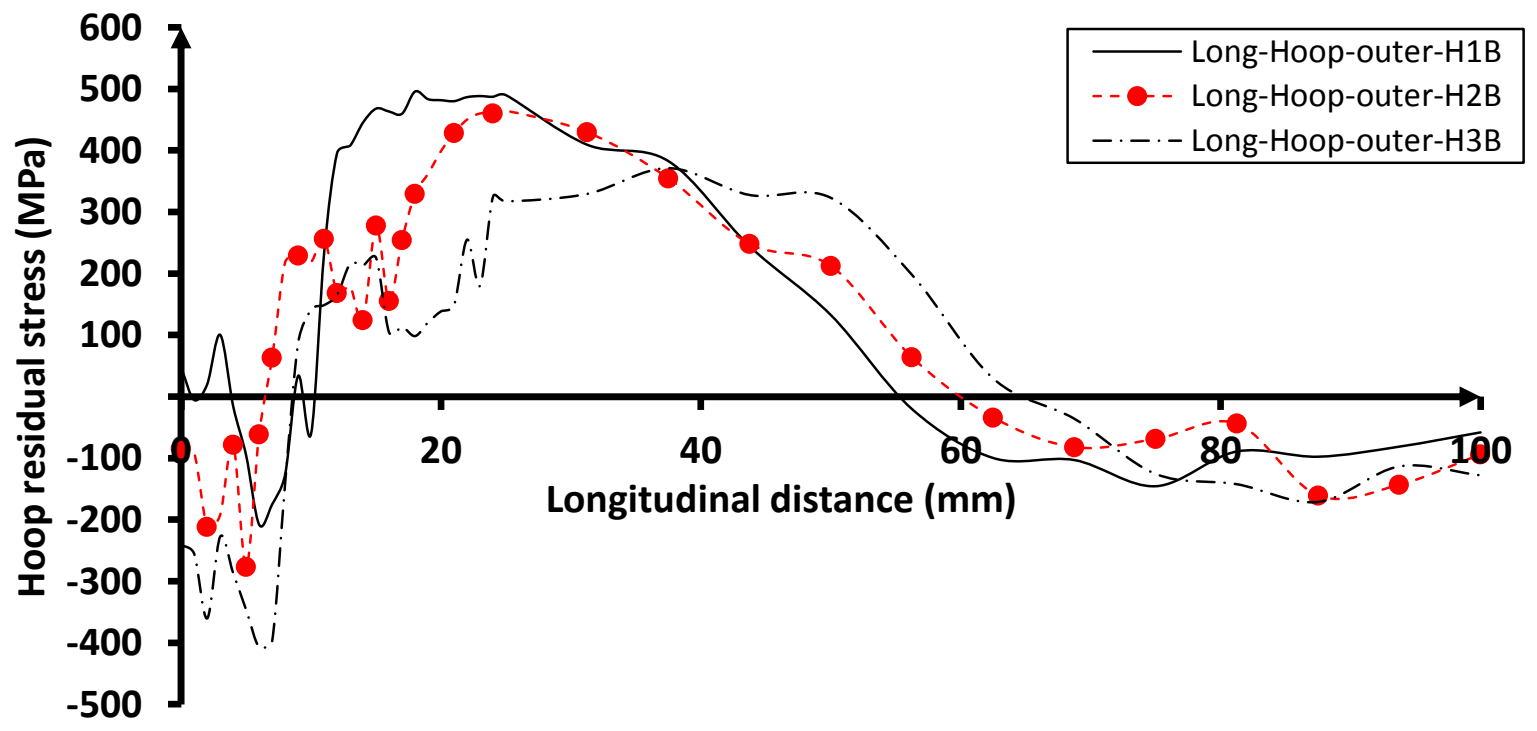


(b)

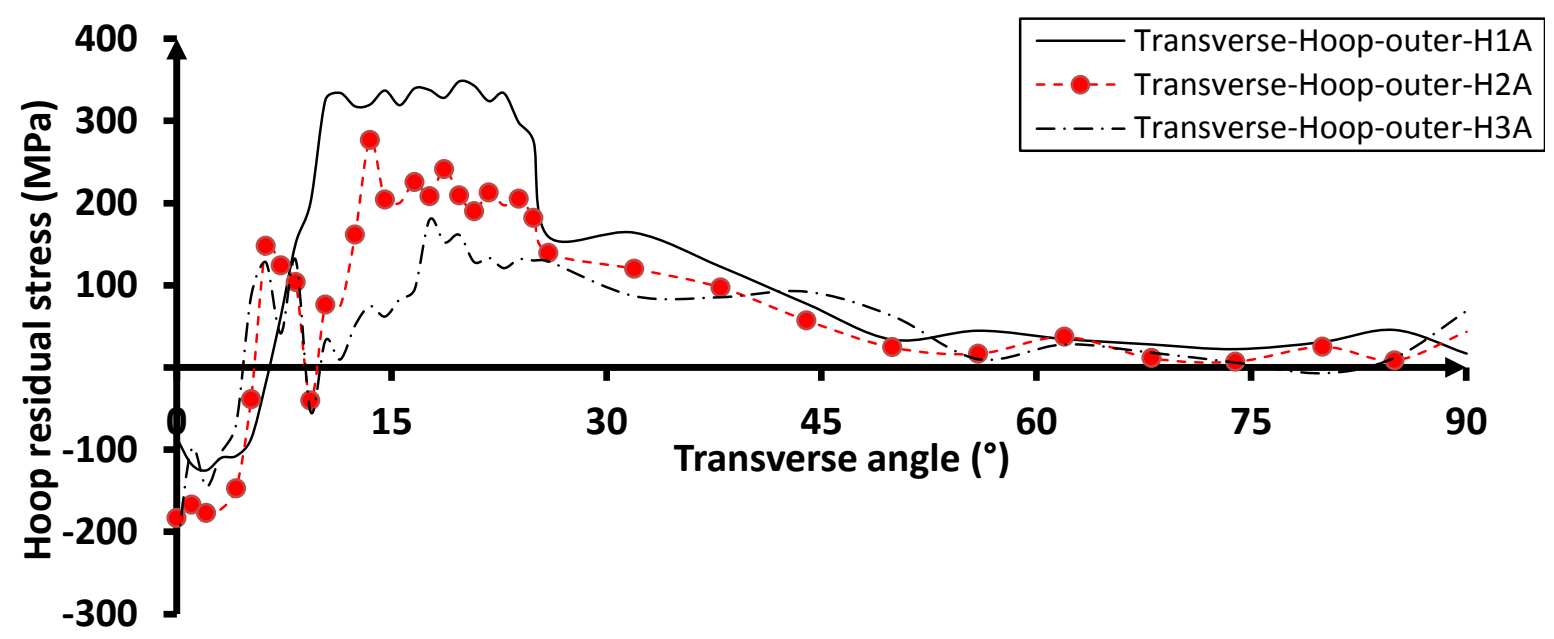

(c)

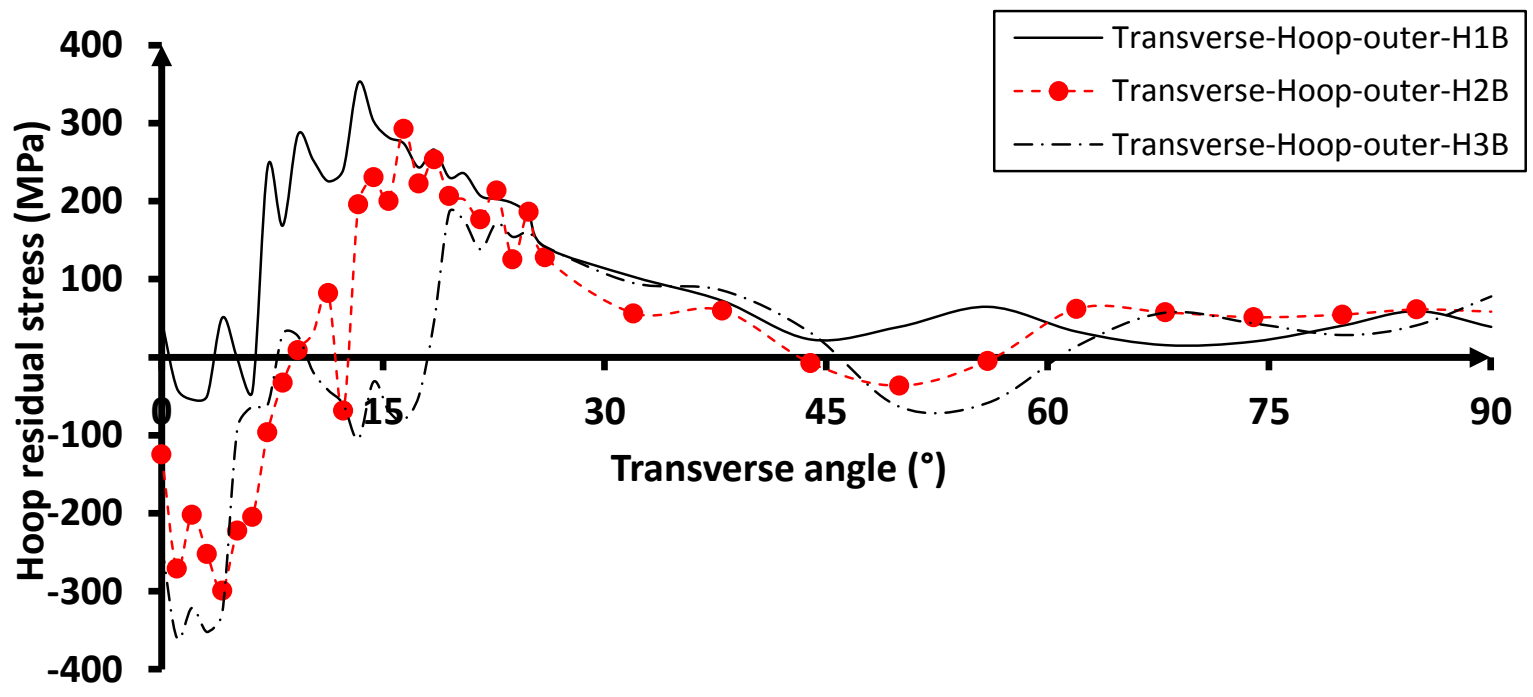

(d)

Fig. 14 Hoop residual stress distribution starting from the dent centre on the outer surface (C-Mn pipe) at (a) the longitudinal planes in case $\mathrm{A}$, (b) the longitudinal planes in case $\mathrm{B}$, (c) the transverse planes in case A and (d) the transverse planes in case B.

A concise summary of the forgoing discussion is that the onset of the cracks is most likely to be at the dent periphery and to propagate predominantly along the longitudinal direction on the outer surface, where the tensile residual hoop stresses are higher than their counterparts around the transverse direction.

\subsection{Energy stored and dissipated in the whole model}

In our work, the total energy, $E_{T O T}$, stored and dissipated in the whole model during the impact is composed of different types given as follows: 


$$
\begin{gathered}
E_{T O T}=E_{I}+E_{V D}+E_{K E}+E_{F D}-E_{W}=\text { constant } \\
E_{I}=E_{S E}+E_{P D}
\end{gathered}
$$

where $E_{I}, E_{V D}, E_{K E}, E_{F D}, E_{W}, E_{S E}$ and $E_{P D}$ are the internal energy, viscous dissipation energy, kinetic energy, frictional dissipation energy, work energy, recoverable (elastic) strain energy and plastic dissipation energy, respectively. Other types of energy have not been discussed in this section or considered in the FE model because their changes are either zero or close to zero.

Fig. 15(a)-(d) represents the evolution of all the energy terms during the first strike in the impact test. It is clear that the kinetic energy is equal to the total energy at the beginning of contact between the indenter and pipe. Moreover, after $7.5 \mathrm{~ms}$ first strike is completed and most of the kinetic energy is absorbed and converted into other forms of energy and plastic deformation.

Fig. 15(a) may help to shed light on the types of energy during the first strike in case H1A. As discussed, the kinetic energy starts with $1600 \mathrm{~J}$ to drop rapidly to zero after $7.5 \mathrm{~ms}$. Meanwhile, the energy internally stored or dissipated rises rapidly up from zero to reach the maximum value, $1650 \mathrm{~J}$, at $7.5 \mathrm{~ms}$. The majority of this internal energy is consumed as plastic dissipation energy, around $86 \%$ at $7.5 \mathrm{~ms}$. This energy is used to form the dent and other permanent deformations in the pipe, such as ovalizing the pipe. The elastic strain energy is responsible for the rebound the dent depth after the strike. The work energy is composed of the work of the penalty contact forces and the external work done by the indenter, which reaches its maximum after $9 \mathrm{~ms}$.

In order to examine the effect of using the liner, it could be seen that the internal energy is increased by $3 \%$ in case $\mathrm{H} 1 \mathrm{~B}$ corresponding to its counterpart in case $\mathrm{H} 1 \mathrm{~A}$, when forming the maximum dent depth, after $7.5 \mathrm{~ms}$, as shown in Fig. 15(d). This increase is attributed to the increase in plastic energy which is applied to deform two pipes. Furthermore, the penalty contact between the AISI304 pipe and C-Mn pipe on the entire length has a significant effect on the work energy and the viscous dissipation energy in case H1B. The frictional energy increases slightly with increasing friction between the C-Mn pipe and the indenter. It could be seen that the frictional energy is doubled in case H1A with respect to that of H1B where the dent depth is larger. 
In all tests, increasing the height of the free load drop leads to an increase in the kinetic energy, which in turns raises the value of the plastic dissipation energy. The other types of energy have almost the same values in all cases.

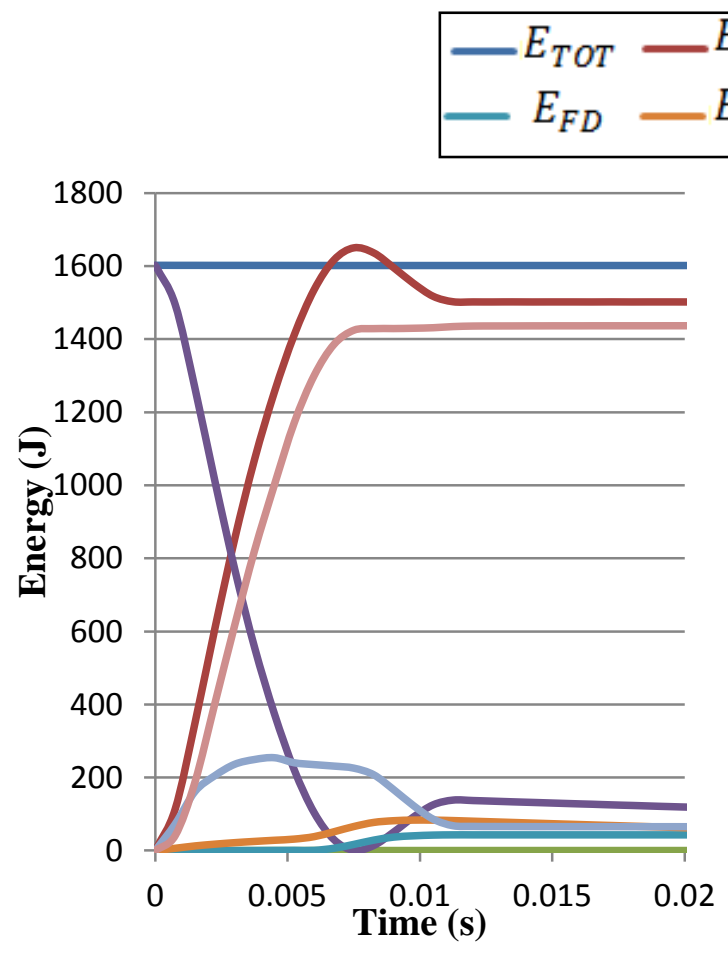

(a)

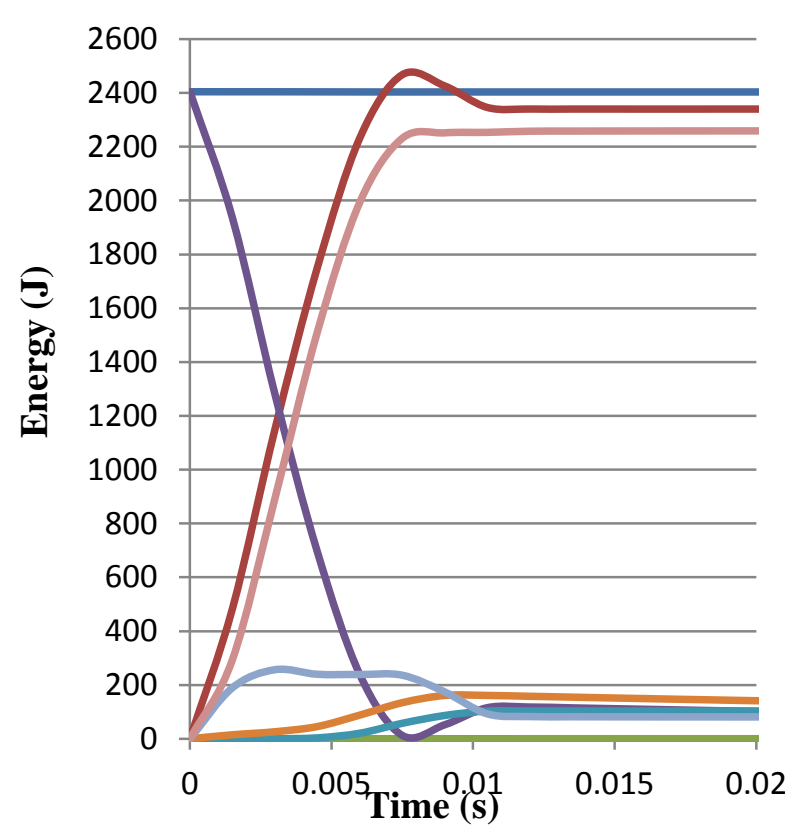

(b)

$$
\begin{aligned}
& E_{I}-E_{V D}-E_{K E} \\
& E_{W}-E_{S E}-E_{P D}
\end{aligned}
$$

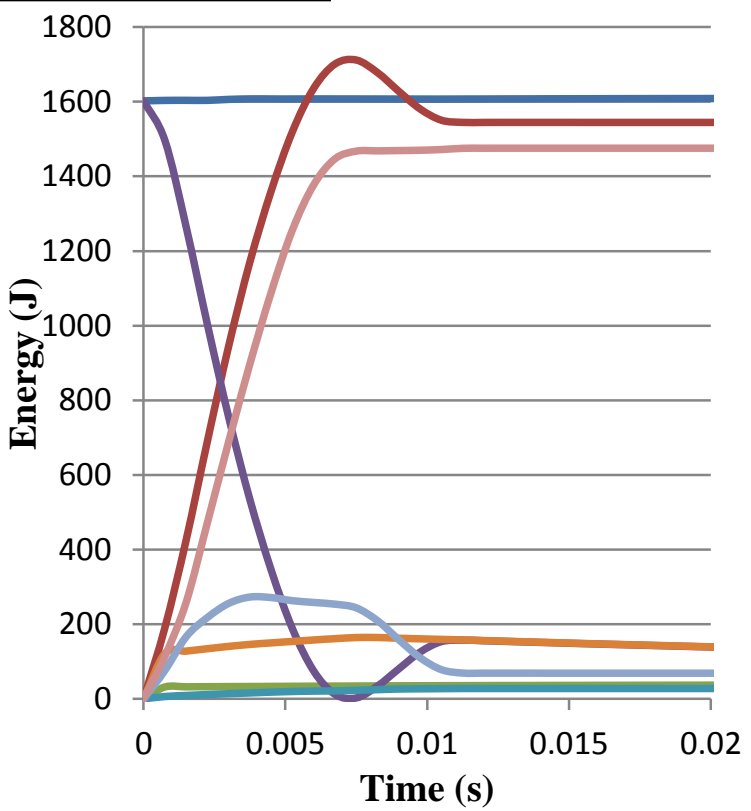

(d)

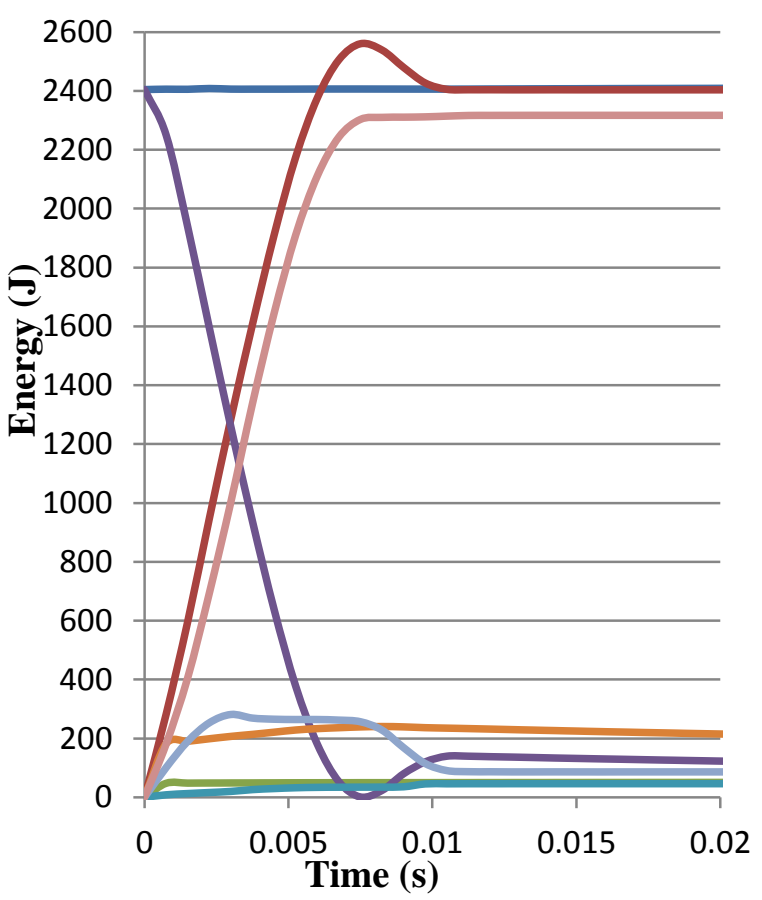

(e) 


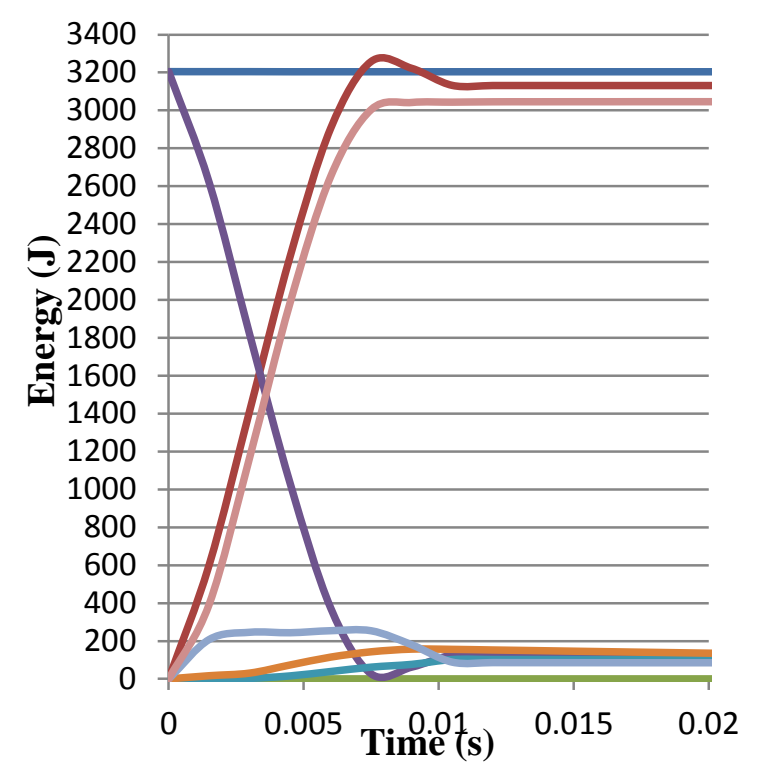

(c)

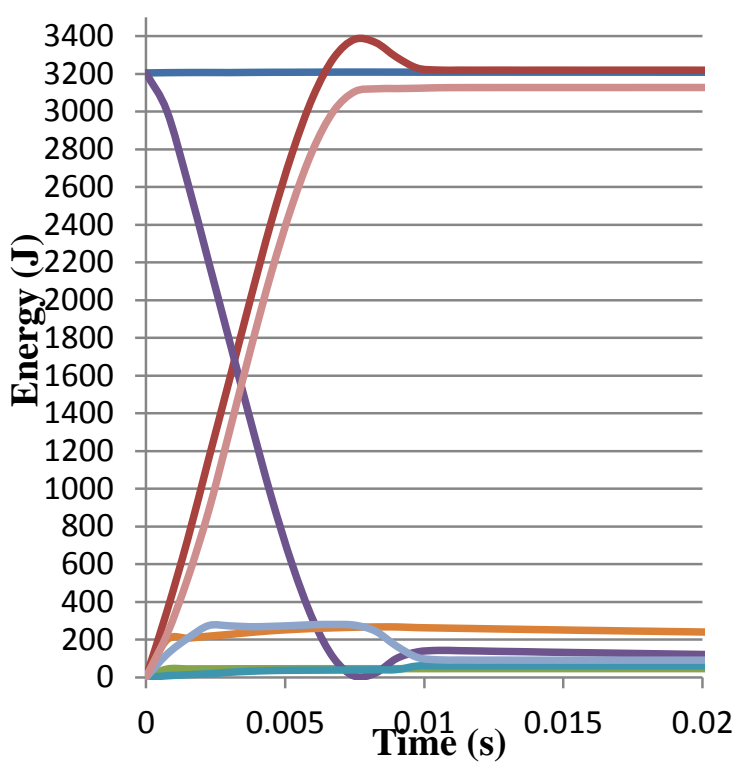

(f)

Fig. 15 Energy absorption in the whole model in test (a) H1 A, (b) H2A, (c) H3A, (d) H1B, (e) H2B and (f) H3B.

\subsection{Collison velocity}

The dynamic impact test is characterized by a series of sequential strikes between the pipe and indenter, hitting the pipe with different velocity at every strike. Fig. 16(a)-(f) shows the changes in the indenter velocity during the impact test starting from the moment when the indenter hits the pipe. It is clear from Fig. 16(a)-(f) that the dent centre in the pipe without liner (case A) has more intensive oscillations in velocity than that in the lined pipe (case B). This can be attributed to the absence of the self-weight of the liner, AISI304 pipe, in case A which in turn enables the C-Mn pipe to bounce after the first strike with larger velocities comparing to their counterparts in case B. Moreover, the strikes in case A cause a deeper depth of dent, which in turn increases the width of pipe and urges the pipe to hit and contact the side plates through the entire impact process.

It can be seen from Fig. 16(a) that the indenter hits the pipe with velocity of $-4 \mathrm{~m} / \mathrm{s}$ (negative because downward) and forces the dent centre to deform downwards with the same velocity of the indenter for $7.5 \mathrm{~ms}$ from the beginning of first strike. After that, both the pipe and the indenter go gradually up, with the velocity of pipe relatively lower because of the effect of collision between the pipe and side plates. After $133 \mathrm{~ms}$, the indenter starts to drop freely down (negative velocity) whilst the pipe in this moment bounces up, then down at $185 \mathrm{~ms}$ and then again up at $236 \mathrm{~ms}$ to meet the indenter at $252 \mathrm{~ms}$ over the ground. The pipe then reaches the ground with the same speed of indenter, $-2.7 \mathrm{~m} / \mathrm{s}$ and the second strike occurs on 
the ground at $258 \mathrm{~ms}$. Ratcheting of the velocity of the indenter tip slightly up and down is attributed to the resistance of the pipe to follow the direction of indenter especially when both the pipe and the indenter are in contact over the ground. The same observations can be repeated for the successive collisions with decreasing velocity of the indenter every time.

The preceding discussion applies to other pipes in cases A and B. It can be observed in all cases that increasing the height of free drop leads to an increase in the number of successive collisions. The times between the successive strikes in case B are longer than their counterparts in case A. It can also be seen that the velocity of the indenter does not oscillate in case $\mathrm{B}$ because there is no significant resistance by the lined pipe.

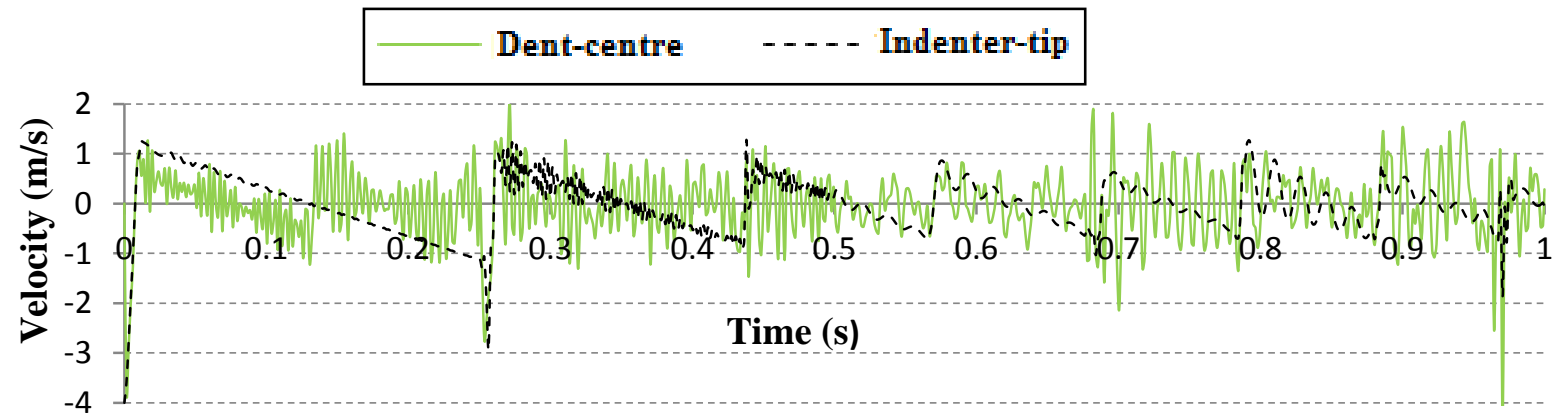

(a)

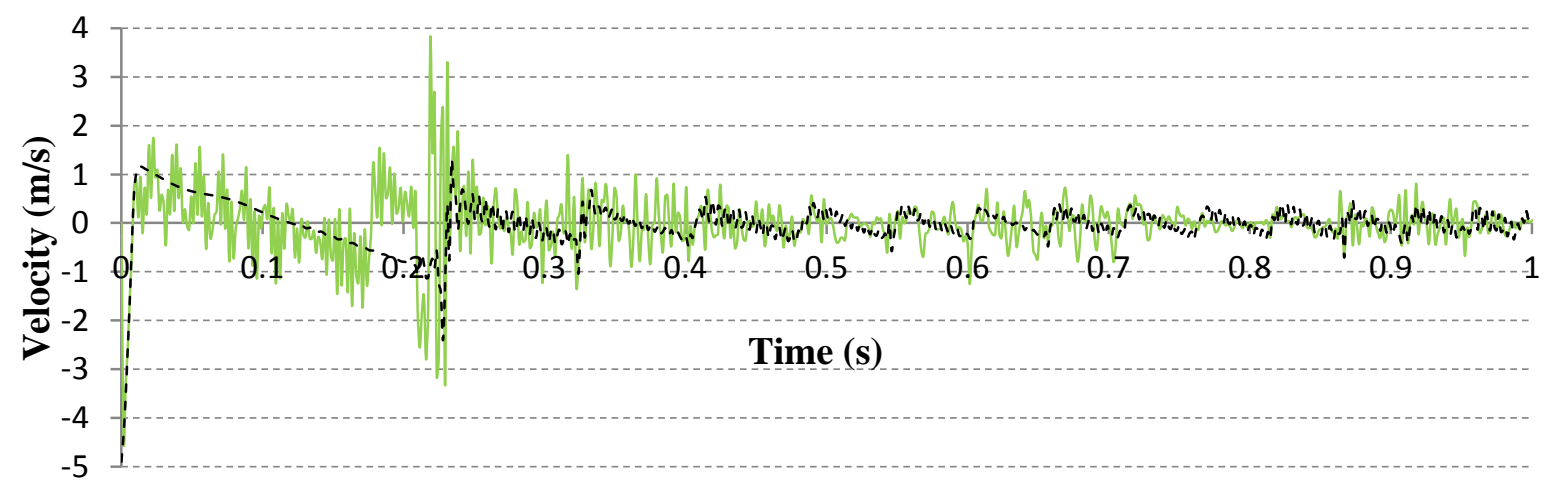

(b)

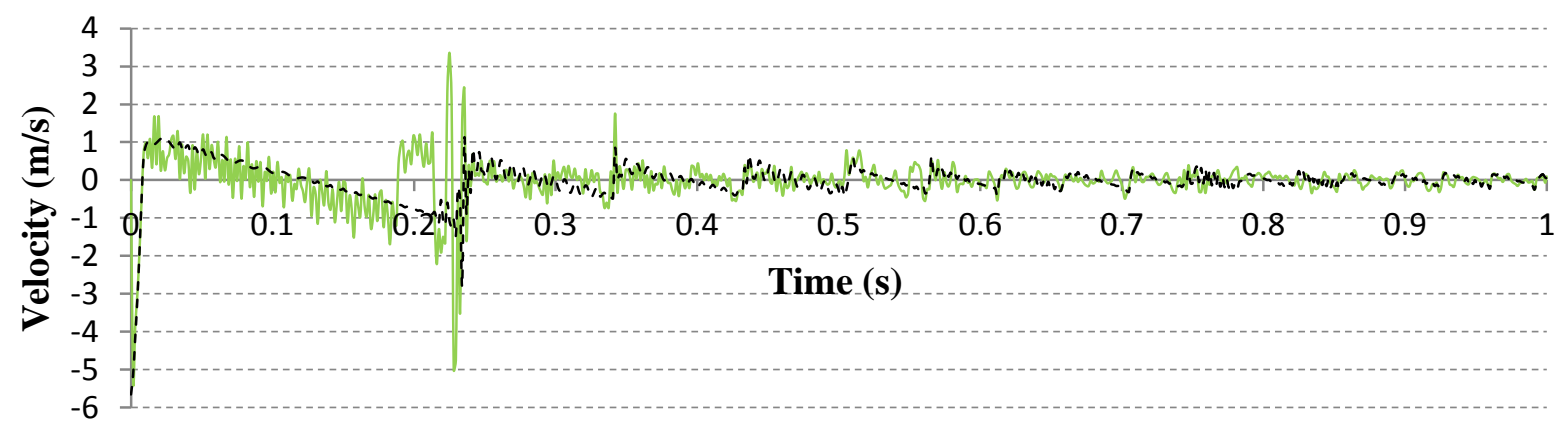

(c) 


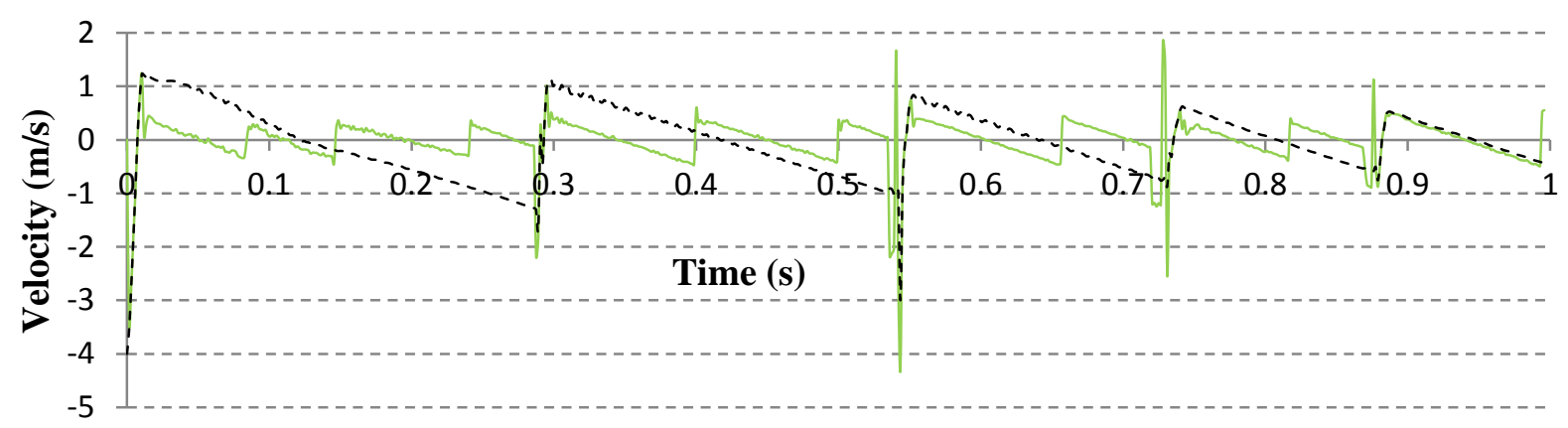

(d)

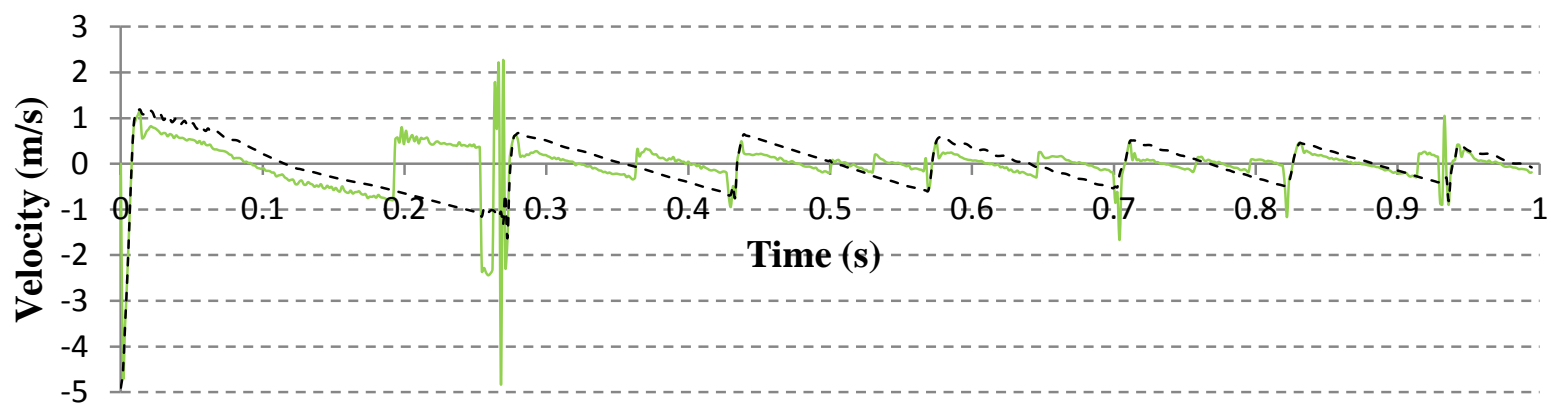

(e)

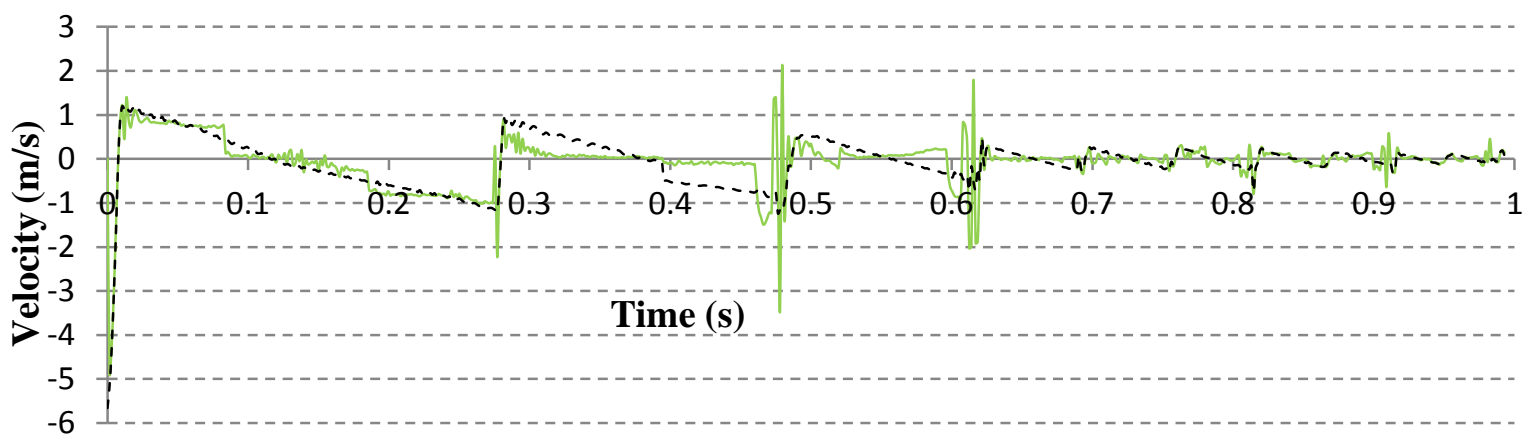

(f)

Fig. 16 Velocity of dent centre and indenter-tip during the first minute of impact in test (a) H1A, (b) $\mathrm{H} 2 \mathrm{~A}$, (c) H3A, (d) H1B, (e) H2B and (f) H3B.

\section{Mesh convergence analysis}

To verify the accuracy of the FE results, two coarse meshes have been used for case H1A in addition to the more refined one used to produce the results presented in the previous sections. The C-Mn pipe in the refined mesh, first coarse mesh, and second coarse mesh is discretised with 7488, 2700 and 1064 nodes associated with 5355, 1680 and 486 elements, respectively, as shown in Fig. 17. The element sizes in the first and second coarse meshes, denoted as $1.5 \mathrm{~h}$ and $2 \mathrm{~h}$, are equal to or larger than 1.5 times and 2 times that of the refined mesh, denoted as $1 \mathrm{~h}$. 


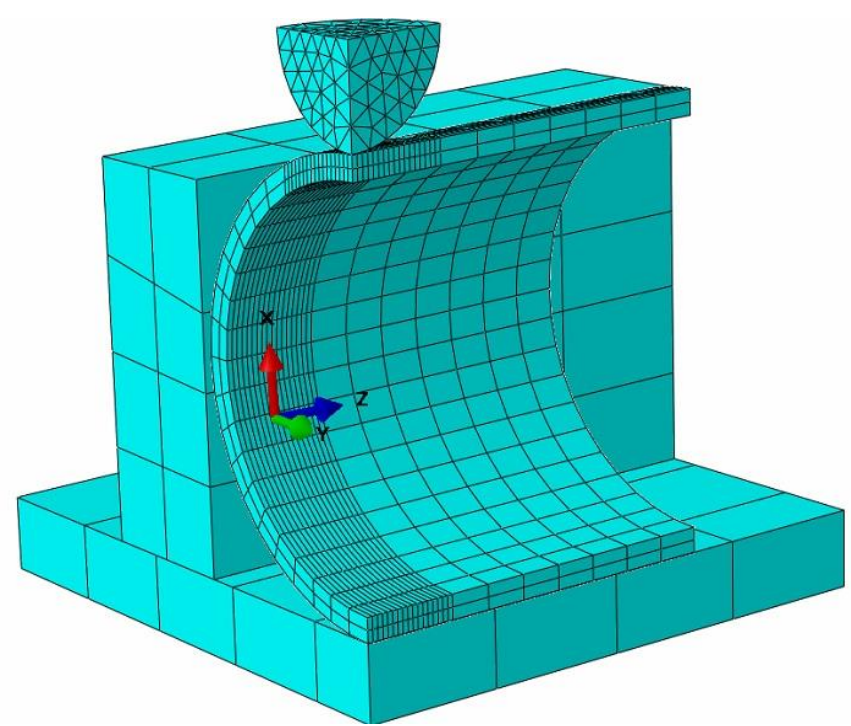

(a)

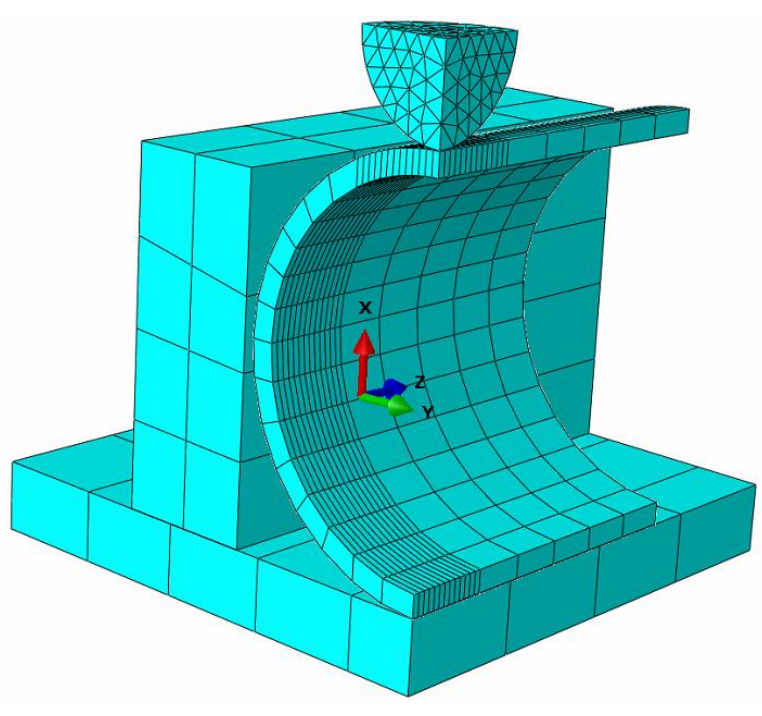

(b)

Fig. 17 Coarse mesh of the quarter lined pipe model of case H1A with (a) $1.5 \mathrm{~h}$ size and (b) $2 \mathrm{~h}$ size.

Comparing the strain results obtained with the three meshes at the GR1 location, it can be observed that the axial and hoop strains of the $1.5 \mathrm{~h}$ mesh model are extremely close to the results of the refined mesh. It can also be seen there is a remarkable variation in the results between the $2 \mathrm{~h}$ mesh model and the normal mesh model, with an absolute increase of $43 \%$ and $11 \%$ in the axial and hoop strain results, respectively, as shown in Fig. 18.

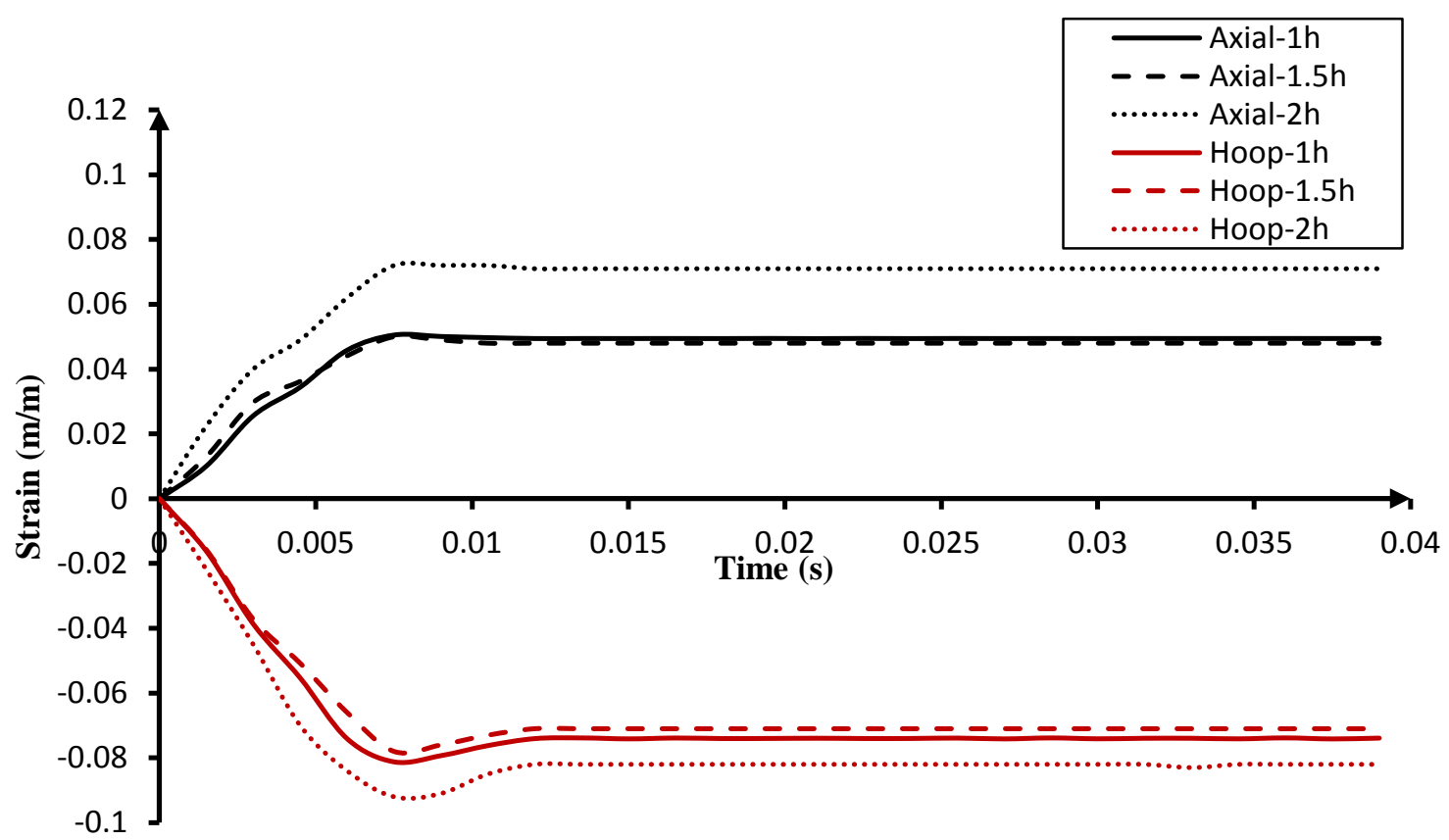

Fig. 18 Axial and hoop strain histories of case H1A at Rosette GR1 location for three mesh sizes.

Consequently, the normal mesh used in all cases in impact models can be considered appropriate to obtain sufficiently accurate numerical results. 


\section{Verification of the experimental results}

In order to validate the accuracy of experimental results obtained in this study, the impact tests were repeated three times for cases $\mathrm{H} 1 \mathrm{~A}$ and $\mathrm{H} 1 \mathrm{~B}$ under the same conditions every time. Fig. 19 and Fig. 20 depict the axial and hoop strain distributions at rosette GR1 in cases H1A and H1B for three tests, respectively.

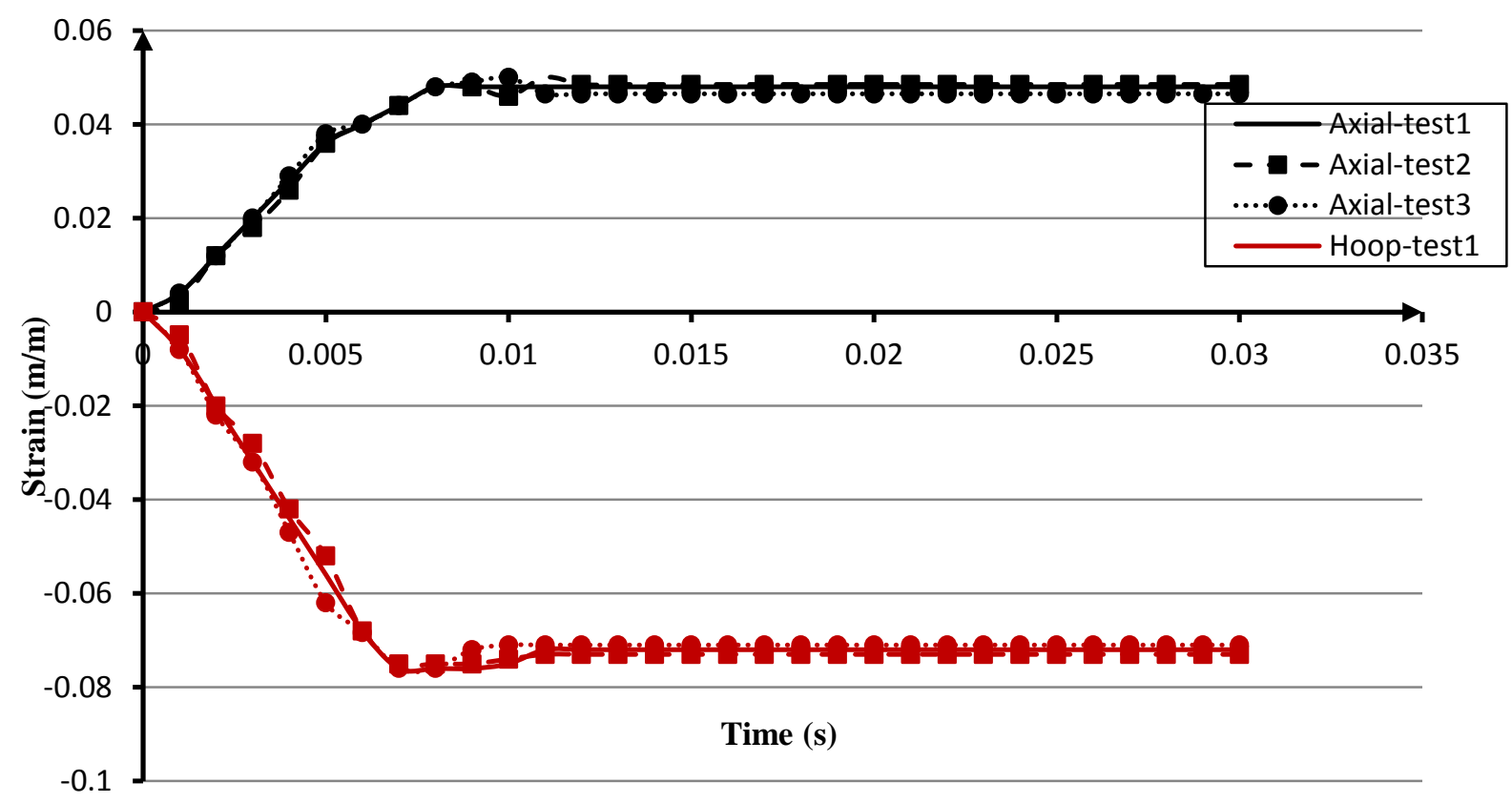

Fig. 19 Strain results of repeated test for case H1A at rosette GR1.

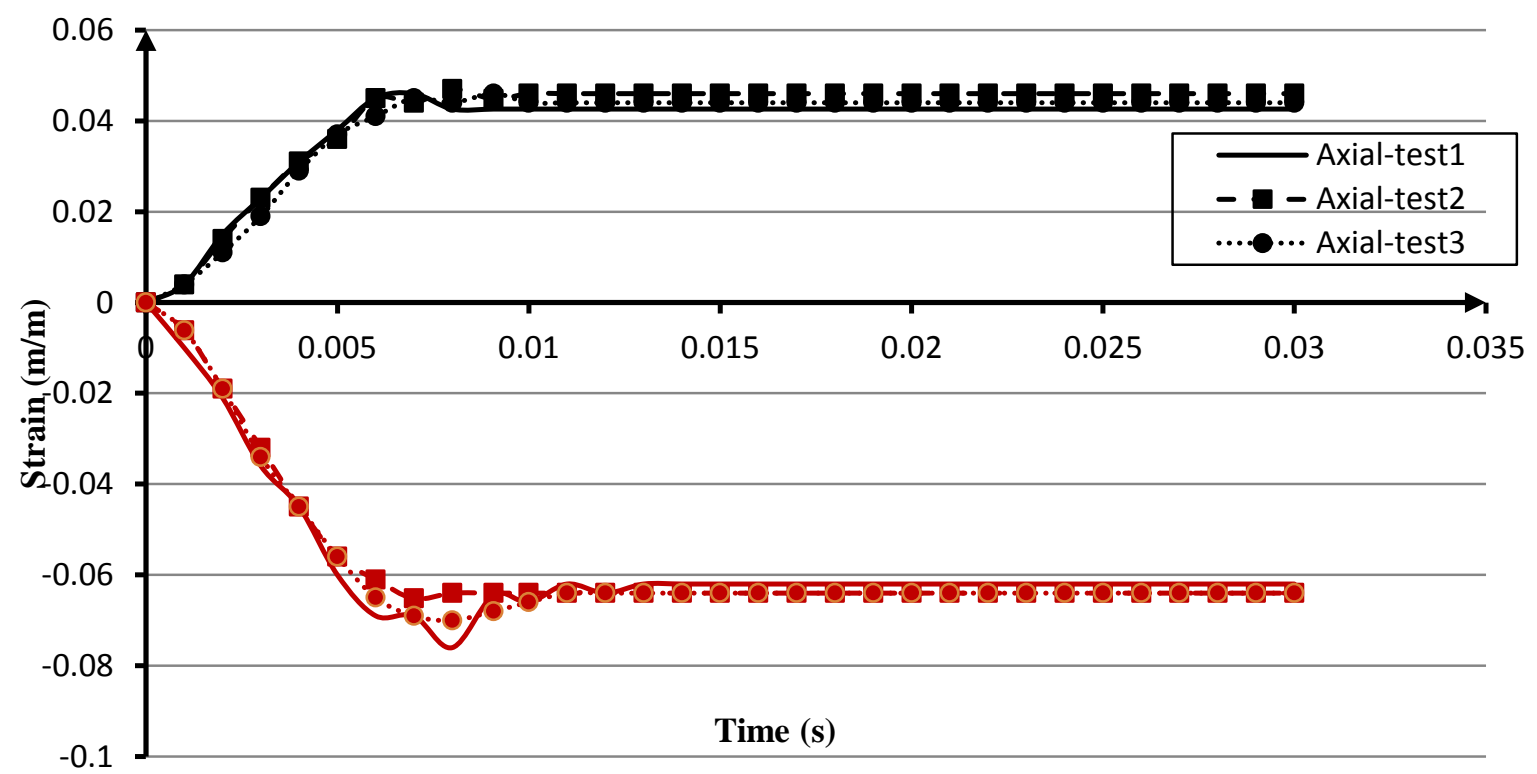

Fig. 20 Strain results of repeated test for case H1B at rosette GR1. 
From Figs. 19 and 20, it could be seen that there is a very good correlation among all repeated tests, which in turn confirm the reliability of the experimental procedure used and, therefore, of the other experimental results.

\section{Conclusions}

In this work, the results of an experimental and numerical study of the impact of a $200 \mathrm{~kg}$ weight freely dropped from different heights over lined pipe specimens has been reported and analysed, including in particular the evaluation of the stress/strain behaviour in the dented region. The effect of the liner on the dynamic impact process has also been investigated. The numerical strain results have been compared with the experimental ones recorded by four strain gauge rosettes positioned symmetrically around the dent centre. The various types of energy dissipation and the velocity of impact process have also been evaluated and discussed. The reliability of our numerical and experimental findings in this work is confirmed by the results of a mesh convergence analysis and of repeated dynamic impact tests, respectively.

The following main conclusions can be drawn:

(1) There is a very good correlation between the numerically predicted deformed geometries and the experimental ones in all cases. Increasing the dropping height leads to an increase in the ratio of dent depth-to-pipe outside diameter which is over $10 \%$ in all case. With this ratio, all cases have a high susceptibility to burst in service according to EPRG [17].

(2) During the first strike of the impact process, it is evident that the pipe permanently and plastically deforms to form a dent characterized by tangential compressive strains to the dent periphery and perpendicular tensile strains to it. Also, increasing the dropping height leads to increase in the strain value. Due to the effect of the liner, the absolute values of strain in case A are larger than their counterparts in case B associated with the same altitude.

(3) The higher concentration of residual stresses is located at the dent perimeter on the top surface of pipe. At the dent periphery, the longitudinal plane has significant higher tensile hoop residual stresses than the transverse plane. 
(4) Due to deformation of the two pipes together, the energy absorbed by plastic deformation in case B (with liner) is higher by $3 \%$ than that in case A whilst the elastic strain energy to a large extent remains the same in all cases.

(5) Removing the liner enables the $\mathrm{C}$-Mn pipe to bounce higher. Furthermore, the time elapsed between the actual successive strikes is significantly shorter in case A than that in case B (with liner).

\section{References}

[1] Obeid, O., Alfano, G. and Bahai, H., 2014. Analysis of the temperature evolution during lined pipe welding. In Advanced Materials Research (Vol. 1016, pp. 753-757). Trans Tech Publications. doi: www.scientific.net/AMR.1016.753

[2] Obeid, O., Alfano, G. and Bahai, H., 2017. Thermo-Mechanical Analysis of a Single-Pass Weld Overlay and Girth Welding in Lined Pipe. Journal of Materials Engineering and Performance, 26(8), pp.3861-3876. doi: http://doi.org/10.1007/s11665-017-2821-5

[3] Obeid, O., Alfano, G., Bahai, H. and Jouhara, H., 2017. Numerical simulation of thermal and residual stress fields induced by lined pipe welding. Thermal Science and Engineering Progress. doi: http://doi.org/10.1016/j.tsep.2017.10.005

[4] Obeid, O., Alfano, G., Bahai, H. and Jouhara, H., 2017. A parametric study of thermal and residual stress fields in lined pipe welding. Thermal Science and Engineering Progress. doi: http://doi.org/10.1016/j.tsep.2017.10.011

[5] PHMSA Pipeline Safety Program Pipeline Safety Incident Reports, Pipeline and Hazard Materials Safety Administration, 2007, Available from http://www.phmsa.dot.gov/.

[6] Durkin, S., 1987. An analytical method for predicting the ultimate capacity of a dented tubular member. International journal of mechanical sciences, 29(7), pp.449-467. doi: http://doi.org/10.1016/00207403(87)90008-7

[7] Seng, O.L., Wing, C.Y. and Seet, G., 1989. The elastic analysis of a dent on pressurised pipe. International journal of pressure vessels and piping, 38(5), pp.369-383. doi: http://doi.org/10.1016/0308-0161(89)900471

[8] Fowler, J.R., Alexander, C.R., Kovach, P.J. and Connelly, L.M., 1995. Fatigue life of pipelines with dents and gouges subjected to cyclic internal pressure (No. CONF-950116--). American Society of Mechanical Engineers, New York, NY (United States).

[9] Netto, T.A., Ferraz, U.S. and Estefen, S.F., 2005. The effect of corrosion defects on the burst pressure of pipelines. Journal of constructional steel research, 61(8), pp.1185-1204. doi: http://doi.org/10.1016/j.jcsr.2005.02.010 
[10] Pinheiro, B.D.C. and Pasqualino, I.P., 2009. Fatigue analysis of damaged steel pipelines under cyclic internal pressure. International Journal of Fatigue, 31(5), pp.962-973. doi: http://doi.org/10.1016/j.ijfatigue.2008.09.006

[11] Allouti, M., Schmitt, C., Pluvinage, G., Gilgert, J. and Hariri, S., 2012. Study of the influence of dent depth on the critical pressure of pipeline. Engineering Failure Analysis, 21, pp.40-51. doi: http://doi.org/10.1016/j.engfailanal.2011.11.011

[12] Dassault Systèmes (2014) ABAQUS 6.14 Analysis User's Guide, Volume III: Materials. USA.

[13] Darabi, R., Azodi, H.D. and Bagherzadeh, S., 2017. Investigation into the effect of material properties and arrangement of each layer on the formability of bimetallic sheets. Journal of Manufacturing Processes, 29, pp.133-148. doi: http://doi.org/10.1016/j.jmapro.2017.07.022

[14] Li, J., Liu, H., Shen, Z., Qian, Q., Zhang, H. and Wang, X., 2016. Formability of micro-gears fabrication in laser dynamic flexible punching. Journal of Materials Processing Technology, 234, pp.131-142. doi: http://doi.org/10.1016/j.jmatprotec.2016.03.018

[15] Handbook, M., 1973. Vol. 8. ASM, Metals Park, OH, 263.

[16] Wiesner, C.S. and MacGillivray, H., 1999, April. Loading rate effects on tensile properties and fracture toughness of steel. In 7 th Symposium on Fracture, Plastic Flow and Structural Integrity (pp. 149-173).

[17] Roovers, P., Bood, R., Galli, M., Marewski, U., Steiner, M. and Zaréa, M., 2000. EPRG methods for assessing the tolerance and resistance of pipelines to external damage. Pipeline technology, 2, pp.405-425.

[18] Allouti, M., Schmitt, C. and Pluvinage, G., 2014. Assessment of a gouge and dent defect in a pipeline by a combined criterion. Engineering Failure Analysis, 36, pp.1-13. doi:

http://doi.org/10.1016/j.engfailanal.2013.10.002

[19] Pinheiro, B., Pasqualino, I. and Cunha, S., 2014. Fatigue life assessment of damaged pipelines under cyclic internal pressure: Pipelines with longitudinal and transverse plain dents. International Journal of Fatigue, 68, pp.38-47. doi: http://doi.org/10.1016/j.ijfatigue.2014.06.003

[20] Pipeline transportation systems for liquids and slurries. (2012). New York: American Society of Mechanical Engineers.

[21] Gas Transmission and Distribution Piping Systems. (2010). American Society of Mechanical.

[22] Tian, X. and Zhang, H., 2017. Failure pressure of medium and high strength pipelines with scratched dent defects. Engineering Failure Analysis, 78, pp.29-40. doi: http://doi.org/10.1016/j.engfailanal.2017.03.010

[23] Wu, Y., Xiao, J. and Zhang, P., 2016. The analysis of damage degree of oil and gas pipeline with type II plain dent. Engineering Failure Analysis, 66, pp.212-222. doi:

http://doi.org/10.1016/j.engfailanal.2016.04.004

[24] Kristoffersen, M., Børvik, T., Langseth, M. and Hopperstad, O.S., 2016. Dynamic versus quasi-static loading of X65 offshore steel pipes. The European Physical Journal Special Topics, 225(2), pp.325-334. doi: http://doi.org/10.1140/epjst/e2016-02629-4 